\title{
¿SOMOS PRISIONEROS DE NUESTRA IDENTIDAD? MINORÍAS CULTURALES, REPUBLICANISMO Y CONSTITUCIONALISMO DEMOCRÁTICO*
}

\author{
PRISONERS OF OUR IDENTITY? MULTICULTURALISM, \\ REPUBLICANISM AND DEMOCRATIC CONSTITUTIONALISM
}

Juan M. MocoroA**

\begin{abstract}
Resumen:
En este trabajo se presentan los elementos definitorios del liberalismo y comunitarismo, a partir del desafío de reconocimiento de las minorías culturales. Para tales efectos, recurro a algunos autores representativos de ambas posiciones. Luego, intento ofrecer una respuesta institucional que podría brindar el llamado constitucionalismo político. A esta posición, la vinculo con la filosofía política republicana. La finalidad de esta reconstrucción es defender una posición suficientemente política que pueda dar fundamento a fuertes lealtades constitucionales basadas en (lo que Habermas llama) el patriotismo constitucional. Se propone pensar que la ventaja que tiene el recurrir a esta idea es que genera lazos comunitarios y lealtad constitucional sin que, por ello, deba comprometerse con algunos de los problemas que se señalan respecto a las versiones competitivas.

* Artículo recibido el 11 de febrero de 2014 y aceptado para su publicación el 13 de octubre de 2014.

** Abogado (Universidad Nacional de Córdoba), Master in Global Rule of Law and Constitutional Democracy (Università degli Studi di Genova), doctorando en derecho (UNC), docente de Derecho Constitucional y Derecho Procesal IV (UNC y UESiglo21, Argentina).jmmocoroa@gmail.com.

Agradezco a Andrés Rossetti y, particularmente, a Cristina Redondo que leyeron una versión anterior de este trabajo y me efectuaron importantes observaciones, críticas y sugerencias que, al menos espero, lo mejoraron formal y sustantivamente. Por último, mi más sincero reconocimiento para el evaluador anónimo fijado por la dirección editorial de esta publicación; él ayudó no sólo a mejorar el texto sino, también, a clarificar mis propias ideas.
\end{abstract}


JUAN M. MOCOROA

\section{Palabras clave:}

Multiculturalismo, liberalismo, comunitarismo, constitucionalismo político, republicanismo, identidad colectiva.

\section{Abstract:}

In this article I outline the defining features of liberalism and communitarianism concerning the challenge of recognizing cultural minorities. To that end, I draw on the work of important advocates of both approaches. Then, I try to elaborate an institutional position from the view of political constitutionalism, which is associated to republicanism. My goal is to defend a political view that grounds a strong attachment to the Constitution or (what Habermas calls) "constitutional patriotism". The advantages of this view, I believe, is that it generates solidarity among citizens and loyalty to the Constitution avoiding the problems I have found in contending approaches.

Keywords:

Multiculturalism, Liberalism, Communitariarism, Political Constitutionalism, Republicanism, Collective Identity. 
¿SOMOS PRISIONEROS DE NUESTRA IDENTIDAD?

SUMARIO: I. Introducción. II. Dos posiciones antagónicas: asimilación vs. reconocimiento. III. Un intento de respuesta: Rawls y la justicia política. IV. La necesidad del reconocimiento y la posición de Charles Taylor. V. Deliberación política, republicanismo y heterogeneidad cultural. VI. Conclusiones. VII. Referencias bibliográficas.

\section{INTRODUCCIÓN}

Es un hecho notorio que las sociedades contemporáneas se caracterizan por la presencia de desacuerdos muy profundos sobre las diferentes concepciones de justicia que apoyan sus integrantes. ${ }^{1}$ En efecto, estos apoyan sus creencias en distintas doctrinas filosóficas, religiosas y políticas. Sin embargo, si bien suelen ser presentadas como conflictivas e inconmensurables entre sí, también parece inevitable aceptar que muchas de esas concepciones pueden ser consideradas razonables. La generalización de un "pluralismo razonable" del que nos habla Rawls, entonces, parece inevitable. ${ }^{2}$

Por eso, no podemos pensar las sociedades actuales como herméticamente homogéneas. Al menos no, en un sentido fuerte. En particular, cuando aquellas diferencias se apoyan sobre elementos culturales que, en algún sentido, es usual pensar como identitarios y conformadores. De esta manera, los individuos que las integran se adscriben a identidades múltiples que compiten con otros individuos con los que comparten la esfera pública. Incluso esas identidades pueden pensarse como competitivas en el interior de cada uno

1 Cfr. Rawls, John, El liberalismo político, trad. de Antoni Doménech, Madrid, Crítica, 2004, p. 12 ("Una sociedad democrática moderna no sólo se caracteriza por una pluralidad de doctrinas comprehensivas religiosas, filosóficas y morales, sino por una pluralidad de doctrinas comprehensivas incompatibles entre sí y, sin embargo, razonables"). Respecto del desacuerdo sobre concepciones de justicia, Véase Waldron, Jeremy, Derecho y desacuerdos, trad. de José Luis Martí y Águeda Quiroga, Madrid, Marcial Pons, 2005 p. 9.

2 Cfr. Rawls, El liberalismo político, cit., pp. 66 y ss., 94 y ss. (donde distingue el "hecho del pluralismo" y el "pluralismo razonable" -i. e., existen doctrinas comprehensivas razonables sostenidas por personas, también, razonables y que tienden a garantizar los derechos y libertades básicas-). 
JUAN M. MOCOROA

de aquellos; lo que dificulta al extremo la plausibilidad de encasillamientos a priori. No obstante, los defensores de derechos diferenciados para las minorías culturales reclaman por la protección y reconocimiento de los patrones culturales que les sirven de horizonte.

Este es un problema que debe enfrentar cualquier teoría de la justicia que intente dar cuenta de: $a$ ) la necesidad de los ciudadanos de vivir conjuntamente y establecer cursos de acción común, pese a esos desacuerdos, y $b$ ) respetar las diferencias que separan a los integrantes de estas sociedades plurales. Las tareas a encarar, entonces, deben ser dos: $i$ ) determinar si las instituciones públicas debieran reconocer de algún modo esas "identidades diferenciadas", y, si se responde a $i$ ) afirmativamente, ii) cómo debieran hacerlo. ${ }^{3}$ Se trata de balancear adecuadamente las consideraciones más clásicas respecto de los derechos individuales con esas aspiraciones colectivas y comunitarias, en especial, cuando las demandas de reconocimiento son estrategias políticas defendidas por grupos. Es que, en algunas oportunidades, pueden existir conflictos entre esos derechos - favorecidos por el liberalismo político-y algunos (supuestos) derechos colectivos - defendidos por posturas comunitarias-. Entonces, ¿cuáles son los límites morales a la demanda de reconocimiento político de las culturas particulares? ${ }^{4}$ ¿Cómo debe enfrentar una comunidad política estos disensos basados en aspectos culturales? Para algunos defensores de las minorías culturales, este desafío obliga a deber aceptar que, en algún sentido, somos prisioneros de nuestra identidad colectiva.

Esta última intuición es la que cuestionaré en este trabajo. Para ello, primero, presentaré los elementos que caracterizan a cada una de estas posiciones lo más fidedignamente posible. En especial, me ocuparé de reconstruir la posición de Charles Taylor vis à vis la de algunos filósofos liberales. Más tarde, intentaré dar una respuesta tentativa que podría ofrecer institucionalmente el llamado constitucionalismo político. A esta posición la vincularé con el núcleo duro

3 Cfr. Gutmann, Amy, "Introducción", en Taylor, Charles, El multiculturalismo y "la política del reconocimiento", 2a. ed., trad. de Mónica Utrilla de Neira et al., México, Fondo de Cultura Económica, 2009, p. 23.

4 Ibidem, p. 26. 
del pensamiento "republicano", representado por la obra de Phillip Pettit. Mi propósito es rastrear un fundamento suficientemente político que pueda justificar fuertes lealtades constitucionales basadas en (lo que Habermas llama) "patriotismo constitucional". La ventaja que tiene recurrir a esta idea, pienso, es que genera lazos comunitarios y lealtad constitucional sin que, por ello, deba comprometerse con algunos de los problemas que aquejan a aquellas versiones competitivas.

\section{DoS POSICIONES ANTAGÓNICAS: ASIMILACIÓN VS. RECONOCIMIENTO}

Es posible disociar dos concepciones respecto de cómo enfrentar las diferencias culturales en las modernas y plurales sociedades que habitamos y, por tanto, qué trato merecen las minorías culturales en este ámbito. Por un lado, i) una estrategia de asimilación y, por otro, ii) una de estrategia de reconocimiento. Según $i$ ), las diferencias culturales no deberían ser consideradas o tenidas especialmente en cuenta por el sistema institucional. En este sentido, se reclama la existencia de derechos individuales universales y, por tanto, se hace abstracción de las diferencias concretas; a lo sumo, sería posible justificar medidas de acción afirmativa (temporales) ante situaciones de injusticia pasada. ${ }^{5}$ Mientras que, según ii), esas diferencias deben ser especialmente consideradas. Así, presupone que todas las culturas tienen algo importante para decir a todos los seres humanos. Y, entonces, esto debe ser considerado por las instituciones si quieren respetar la diferencia y la autenticidad.

Estas visiones, a su vez, se vinculan con dos formas disímiles de analizar la idea de "igualdad". Por una parte, una que la vincula con la neutralidad política y, por otra, una que fomenta valores culturales particulares. En el trasfondo de ambas cuestiones, como es ob-

5 Sobre las justificaciones de estas acciones y sus dificultades, Sandel, Michael, Justicia ¿Hacemos lo que debemos?, trad. de Juan Pedro Campos Gómez, Barcelona, Debate, 2011, pp. 190 y ss. y El liberalismo y los límites de la justicia, trad. de María Luz Melón, Barcelona, Gedisa, 2000, pp. 171 y ss. Una posición diferente en Dworkin, Ronald, Virtud soberana. La teoría y la práctica de la igualdad, trad. de María Julia Bertomeu, Barcelona, Paidós, caps. 11 y 12. 
JUAN M. MOCOROA

vio, pueden encontrarse dos visiones competitivas en el ámbito de la filosofía política: liberalismo (político) y comunitarismo. ${ }^{6}$

Según la estrategia de la asimilación, no es necesario asegurar de derechos particulares basados en presupuestos culturales. Esta posición es seguida, en líneas generales, por el constitucionalismo moderno de raíz liberal para tratar a estas minorías. En este sentido, propone derechos individuales universales, una concepción de la igualdad ciega a las diferencias sociales $y$, por supuesto, neutralidad estatal respecto de las concepciones del bien y de la vida buena. ${ }^{7}$ Ahora bien, esto trae aparejado varias objeciones; como sostiene Luis Rodríguez Abascal, sería “...incapaz de acomodar la diversidad social y de proporcionar un trato igualitario a sus ciudadanos". ${ }^{8}$ Es que, según algunos autores, por más intuitiva que nos resulte esta "ceguera" es, de hecho, una grosera inequidad. Puesto que "ser ciego a la diferencia no significa igual trato para todos los individuos, cuyas diferencias parecen requerir precisamente no un trato desigual sino diferencial". ${ }^{9}$

La posición de Waldron, por ejemplo, podría ser presa de esta crítica. ${ }^{10}$ Este autor rechaza el alcance que las visiones comunitaristas le otorgan a los derechos culturales. Para él, se trata de posiciones que carecen de claridad conceptual y sus postulados son indeseables desde el punto de vista de la justicia. En sociedades pluralis-

6 Esta contraposición puede extenderse en las raíces del pensamiento filosófico como una disputa con nombre propio: Kant vs. Hegel. Para el primero, existen obligaciones universales que deben prevalecer sobre elementos contingentes derivados de la pertenencia a una comunidad particular. Para el segundo, al contrario, debe darse prioridad a nuestros lazos comunitarios; analizar la cuestión desde un sujeto situado. Cfr. Nino, Carlos S., "Kant versus Hegel, otra vez", La Política. Revista de Estudios sobre el Estado y la sociedad, Barcelona, núm. 1, 1996, pp. 123-135.

7 Cfr. Rodríguez Abascal, Luis, "El debate sobre los derechos de grupo", en Díaz, Elías y Colomer, José Luis (eds.), Estado, justicia, derechos, Madrid, Alianza, 2002, p. 410.

8 Idem.

9 Cfr. Benhabib, Seyla, Las reivindicaciones de la cultura. Igualdad y diversidad en la era global, trad. de Alejandra Vassallo, Buenos Aires, Katz, p. 211.

10 Waldron, Jeremy, "Minority cultures and the Cosmopolitan Alternative", en Kymlicka, Will (ed.), The rights of Minority Cultures, Oxford, Oxford University Press, 1995, pp. 93-119. 
tas y complejas, como las actuales, la realización práctica de estas propuestas no sólo es difícil sino, quizás, imposible. Además, objeta los intentos de conciliación que promueven matizaciones en pos de asegurar algún reconocimiento particular. De este modo, sus críticas se dirigen a autores liberales igualitarios como Kymlicka. ${ }^{11}$ Recuérdese que este autor, en el marco del debate multiculturalismo/liberalismo, ha sostenido que existe cierta equivocidad de los reclamos más habituales de los grupos minoritarios. Del mismo modo, ¿son necesariamente contradictorias ambas posturas? Una respuesta afirmativa, para él, presupone que los principios liberales son inherentemente incompatibles u opuestos con los reclamos de grupos comunitarios. Esto le parece inaceptable. A su modo de ver, es posible justificar acciones positivas a favor de ciertos grupos $\mathrm{y}$, con ello, la protección de cierto ambiente cultural específico. A tal fin, propone distinguir entre "restricciones internas" y "protecciones externas". Las primeras se refieren a las medidas adoptadas por un grupo en contra de los derechos de alguno de sus miembros. Las segundas, importan barreras en defensa de una determinada minoría desaventajada frente a las pretensiones del grupo social más extenso con el cual aquellas conviven.

Para Waldron, este autor comete un non sequitur. De admitir que las opciones de los individuos tienen un significado cultural, no se sigue que deba haber un contexto cultural, definido mediante lenguaje e historia, que le dé un sentido a todas las opciones disponibles. Los materiales culturales están disponibles desde todos los rincones del mundo en cuanto fragmentos, imágenes y trozos de relatos con mayor o menor significado. Ante las dificultes de reconocimiento de derechos especiales de base cultural, debería otorgarse a las minorías culturales un tratamiento semejante al que, históricamente, el liberalismo otorgó a la libertad religiosa. Rechaza, entonces, protecciones especiales a estas minorías. ${ }^{12}$ Sus derechos deberían respetarse, pero esto no implica que el Estado deba intervenir

11 Cfr. Kymlicka, Will, Ciudadanía multicultural, Barcelona, Paidós, 1996, cap. III.

12 Respecto a las relaciones entre la religión y la política, véase Dworkin, Ronald, La democracia posible. Principios para un nuevo debate político, trad. de Ernest Weikert García, Barcelona, Paidós, 2007, pp. 73 y ss. 
JUAN M. MOCOROA

en su promoción o financiamiento para preservarlos. Propone, entonces, mayor neutralidad y tolerancia.

La propuesta es sumamente atractiva. Sin embargo, creo que podría ser acusada por un planteo comunitarista de cometer una especie de petitio principii. Y esto porque, justamente, lo que se denuncia desde estos sectores es la deseabilidad de la propia idea de neutralidad. Vale decir, es justamente lo que está en el centro de la discusión lo que propone Waldron. Además, es difícil ver si la analogía puede llevarse hasta el extremo. Para sus críticos esta propuesta de inacción estatal y mayor neutralidad, como dice Gargarella, es objetable porque $i$ ) no parece genuina respecto de minorías maltratadas históricamente; ii) importa la adopción de, quizás, una asimilación coercitiva, y iii) parecería un modo de protección del status quo. ${ }^{13}$

Al mismo tiempo, la justicia como reconocimiento podría garantizar algunos aspectos que una teoría liberal clásica estaría imposibilitada, dados algunos de sus compromisos y puntos de partida. Por ejemplo, sólo acentuaría los aspectos distributivos de los que una teoría de la justicia vendría a ocuparse reflexivamente. El caso de la obra de John Rawls sería paradigmático en este sentido; en especial, según sus críticos, al identificar las injusticias sociales $-\mathrm{y}$ su correlativo correlato institucional-. ${ }^{14}$ Es que únicamente pondría el acento en las desigualdades, la marginación y, por último, la privación; en todos los casos de origen económico. De ahí que, dadas estas injusticias, las soluciones institucionales que propondrá se vinculan de modo estrecho con ellas; a saber: reestructuración de los ingresos y distribución equitativa de puestos de trabajo.

Esta estrategia, empero, tendría algunos problemas que la inutilizarían en tanto doctrina emancipadora. En especial, asumiría un carácter sumamente restrictivo de las injusticias que deben ser reparadas. Y esto porque, como dije, se ocupa de un único aspecto relevante: el económico. No obstante, deja fuera una serie de aspectos importantes relacionados con la emancipación del ser hu-

13 Cfr. Gargarella, Roberto, Las teorías de la justicia después de Rawls. Un breve manual de filosofía política, Madrid, Paidós, p. 141.

14 Rawls, John, Una teoría de la justicia, trad. de María Dolores González, México, Fondo de Cultura Económica, 2006, passim. 
¿SOMOS PRISIONEROS DE NUESTRA IDENTIDAD?

mano. Además, presupone una concepción del sujeto objetable: el homo oeconomicus -i. e., individuo consumidor de las sociedades poscapitalistas-. Entonces, serían insuficientes sus herramientas para la transformación de los patrones sociales de representación y dominación. ${ }^{15}$ Es así que, sostiene Fraser:

En [los] conflictos "postsocialistas", la identidad de grupo sustituye a los intereses de clase como mecanismo principal de movilización política. La dominación cultural reemplaza a la explotación como injusticia fundamental. Y el reconocimiento cultural desplaza a la redistribución socioeconómica como remedio a la injusticia y objetivo de la lucha política. ${ }^{16}$

Ahora bien, la justicia como reconocimiento, según sus defensores, carecería de esta "estrechez" de miras. En ella conviven armónicamente un doble conjunto de reclamos, en palabras de Fraser, redistribución y reconocimiento. Si bien consideraría que las desigualdades económicas son un problema que debe resolver una teoría de la justicia, esto es producto de otras injusticias que una visión distributivo-céntrica no podría identificar. De tal modo, insisten, la identificación de las injusticias en las modernas y plurales sociedades contemporáneas debe rastrearse hasta causas culturales, ámbitos de dominación, invisibilización de las diferencias y, por último, falta de respeto a la diferencia. Entonces, las soluciones propuestas habrán de ser marcadas por ciertos actos simbólicos destinados no ya a la distribución de los recursos económicos, sino al reconocimiento de las diferencias y que, institucionalmente, se empodere a esos grupos con protecciones diferenciadas. Entonces, las soluciones propiciadas exigen cambios simbólicos, revaloración de los gru-

15 Cfr. Fraser, Nancy, “¿De la redistribución al reconocimiento? Dilemas en tomo a la justicia en una época 'post-socialista'”, en id., Iustitia Interrupta: reflexiones críticas desde la posición "postsocialista”, Santa Fé de Bogotá, Siglo de Hombres Editores, 1997, pp. 17-54. Para un análisis de esta posición, véase Colón-Ríos, Joel I. y Hevia, Martín, "De la redistribución al reconocimiento", en Alegre, Marcelo y Gargarella, Roberto (eds.), El derecho a la igualdad. Aportes para un constitucionalismo igualitario, 2a. ed. ampliada, Buenos Aires, Abeledo Perrot, 2012, pp. 79-90.

16 Cfr. Fraser, “¿De la redistribución al reconocimiento?...”, cit., p. 17. 
JUAN M. MOCOROA

pos, transformar posturas sociales y, además, favorecer una representación diferenciada. ${ }^{17}$

Cómo evaluar estas cuestiones, y sus propuestas institucionales, dividen de forma palmaria dos concepciones de la teoría de la justicia moderna. En particular, sobre los límites a estas exigencias comunitarias. Analíticamente, podríamos distinguir tres posiciones.

Por un lado, la que sostiene que de ningún modo es aceptable que, en procura de la defensa de supuestos derechos colectivos o de minorías culturales, sea posible el desprecio de derechos individuales. ${ }^{18}$ Por ejemplo, como defiende Amy Gutman, no todas las culturas merecen el mismo respeto. En efecto, para ella, no lo merecen las opiniones que en forma flagrante desdeñen los intereses de los demás; porque i) no adoptan en absoluto una auténtica posición moral y ii) hacen afirmaciones empíricas radicalmente inverosímiles. ${ }^{19}$ No se trata de que toda y cualquier cultura amplíe nuestros horizontes morales sino que, únicamente, lo harán aquellas que se muestren respetuosos con los intereses de los demás. De lo contrario, deben ser rechazadas.

Por otro, quienes en caso de conflicto entre derechos individuales y supuestos derechos colectivos de los grupos culturales relevantes, otorgarían preferencia a estos últimos. Aun cuando esto implique la aceptación de hechos que se presentan prima facie como una afrenta a nuestros esquemas morales y conceptuales más básicos.

Y, finalmente, una posición liberal intermedia que en casos de conflictos rechazaría palmariamente la prioridad de derechos colectivos, en caso de que ellos afecten, cuando menos, derechos muy básicos ligados a consideraciones elementales de autonomía. ${ }^{20}$

17 Ibidem.

18 Véase, por ejemplo en este sentido, Vázquez, Rodolfo, Liberalismo, Estado de derecho y minorías, México, Paidós, 2001, p. 123.

19 Cfr. Gutmann, "Introducción", cit.

20 Esta es la posición de diversos autores liberales igualitarios. Por ejemplo, Comanducci, Paolo, "Derechos Humanos y minorías: un acercamiento analítico neoilustrado", trad. de Francesca Galgano, Isonomía. Revista de Teoría y Filosofía del Derecho, núm. 3, 1995, pp. 21-42; Kymlicka, Ciudadanía multicultural, cit. También puede encontrarse un atisbo de esta postura en la jurisprudencia de la Corte Interamericana de Derechos Humanos. Véase Caso de la Comunidad Mayagna (Sumo) 
En esta presentación, surgen de modo esquemático las diferencias entre concepciones liberales y comunitarias. Para estos últimos, los primeros se apoyan sobre una concepción del sujeto a-histórica y atomista; un sujeto desvinculado de su comunidad. La creencia en derechos universales, ni situados ni producto de las prácticas comunitarias en las que aquellos están insertos, sería una ilusión. Este desafío, entonces, parece que puede dirigir dos críticas al liberalismo. Por un lado, una crítica externa, aquí denunciaría la visión del sujeto ya expresada. Y, con esto, sería impotente para lograr el respeto adecuado a la igualdad. Por otro, una crítica interna. El liberalismo no podría garantizar su propia estabilidad. ${ }^{21}$ Es que las diversas concepciones del bien que están presentes en una sociedad cultural heterogénea (como la actual) no puede sustentarse únicamente sobre la idea de neutralidad, sino que, al contrario, deben comprometerse con alguna concepción del bien que favorezca la idea de autenticidad, identidad cultural y, por tanto, lealtad a los grupos de los que los individuos forman parte.

Para algunas posturas comunitarias, sépase, el reclamo liberal por mayor neutralidad ni es inocente ni es aséptico. Por el contrario, so pretexto de promover una concepción de igualdad, importa la consagración de cierta ortodoxia y, consecuentemente, margina planteos heterodoxos. Ahora bien, una posición suficientemente igualitaria debería fomentar la diversidad. En este sentido, por ejemplo, es muy claro Charles Taylor. ${ }^{22}$ Para él, el liberalismo es un "credo militante" en contra de posiciones sustentadas en concepciones culturales diversas. ${ }^{23}$ Una concepción sustentable de la diversidad y de la igualdad

Awas Tingni vs. Nicaragua, sentencia del 31 de agosto de 2001, fondo, reparaciones y costas. Voto razonado conjunto de los jueces Antônio Augusto Cançado Trindade, Máximo Pacheco Gómez y Alirio Abreu Burelli, párr. 14.

21 En palabras de Rawls: “¿[C]ómo es posible que doctrinas comprehensivas profundamente enfrentadas, pero razonables, puedan convivir y abrazar de consuno la concepción política de un régimen constitucional?". Cfr. Rawls, El liberalismo político, cit., pp. 13 y 14.

22 Cfr. Taylor, Charles, "La política del reconocimiento", cit.

23 El ministro de relaciones exteriores de Singapur, W. S. Wong, adoptó esta posición en el segundo Congreso Mundial sobre Derechos Humanos celebrado en Viena en 1993. Ahí sostuvo: "El reconocimiento universal del ideal de derechos hu- 
debería asentarse sobre la presuposición de que todas las culturas "tienen algo importante que decir a los seres humanos". Es que, en muchas ocasiones, bajo el reclamo por derechos colectivos de carácter cultural, subyace una denuncia de hostilidad por parte de ciertas mayorías respecto de minorías políticamente inocuas. De ahí que, en todo caso, requieran acciones positivas destinadas a permitir un ejercicio efectivo de los derechos emergentes de estas condiciones.

Finalmente, la analogía propuesta por Waldron entre religión y cultura es cuestionable. Si bien es posible sostener en el ámbito de la religión que la estructura básica de la sociedad no se comprometa con ninguna concepción particular, no ocurre lo mismo respecto de las "opciones" culturales. En este sentido, no existen estructuras políticas "aculturales" y, al menos indirectamente, existe el peligro de imposición. De ahí que, parecería, es posible decidir no decidir en materia religiosa y, sin embargo, parece al menos dificultoso no hacerlo en materia cultural.

De todos modos, la objeción es otra. Como sostiene Taylor:

El falso reconocimiento o la falta de reconocimiento equivocado pueden causar daño, pueden ser una forma de opresión, que subyugue a alguien en un modo de ser falso, deformado y reducido... [E]l falso reconocimiento no sólo muestra una falta del respeto debido. Puede infligir una herida dolorosa que causa a sus víctimas un lacerante odio a sí mismas. El reconocimiento debido no sólo es una cortesía que debemos a los demás: es una necesidad humana vital. ${ }^{24}$

Ahora bien, para dar cuenta de esa necesidad de reconocimiento, la cuestión teóricamente compleja es si deberían aceptarse todas aquellas prácticas heterogéneas que, incluso, pudieran contravenir intuiciones muy básicas respecto de concepciones arraigadas, liberales e ilustradas, respecto de los derechos universales.

manos puede ser dañino si el universalismo es utilizado para negar o enmascarar la diversidad". Citado por Sen, Amartya, Identidad y violencia. La ilusión del destino, trad. de Verónica Inés Weinstabl y Servanda María de Hagen, Buenos Aires, Katz, 2008, p. 133.

${ }^{24}$ Cfr. Taylor, "La política del reconocimiento", cit., pp. 54 y 55. 
Pensemos en el siguiente ejemplo. ${ }^{25}$ La comunidad indígena $X$ posee una determinada práctica que, algunos de sus miembros, consideran identitaria. Según ella, a partir de la primera menstruación debe considerarse que una niña se transforma en mujer. Esto tiene como consecuencia la posibilidad inalienable de decidir con quién habrá de tener relaciones sexuales; independientemente de cuál sea su edad o desarrollo mental y cognitivo. Ahora bien, para hacer el ejemplo lo suficientemente paradigmático, pensemos que la edad de ella es de once años. Entonces, para la práctica identitaria de esta comunidad, se trataría del ejercicio de una facultad elegir con quién o quiénes tendrán relaciones sexuales. Más allá de esto, pensemos que existen en el Estado en que se encuentra radicada esta comunidad, normas penales que, justamente, consideran "abuso sexual" cuando la víctima del mismo no supere los 13 años de edad. ${ }^{26}$ Para complicar más las cosas, pensemos que existe una norma constitucional que expresamente dispone la necesidad de garantizar la identidad y la pluralidad cultural. ${ }^{27}$ Tenemos, claramente, un caso de conflicto. Para el derecho estatal, se trata de un caso claro de abuso sexual agravado por la edad de la víctima. Sin embargo, de acuerdo a la interpretación de las prácticas identitarias de la comunidad indígena, se trata de una persona que puede seleccionar, autónomamente, con quién tener relaciones sexuales.

Adviértase que ni siquiera la descripción desapasionada del relato puede considerarse aséptica. Es que la calificación de "mujer", "niña", "pequeña" o "víctima" posee una fuerte carga emotiva y, en algún sentido, adopta una posición sobre el asunto. En efecto, para considerar que se trata de una "mujer" debería enfocarse el asunto desde el marco conceptual determinado por la práctica indígena de la comunidad a la que me referí. Por el contrario, considerarla "niña"

25 El ejemplo no es imaginario. Se trata de una presentación exagerada de un caso judicial analizado por los tribunales de la provincia Salta, Argentina. Véase Guiñazú, Claudio, "El sistema penal frente a la diversidad cultural: el caso «Ruiz, J. F.»", en Rossetti, Andrés y Álvarez, Magdalena I. (coords.), Derecho a la igualdad. Un análisis desde el método de casos, Córdoba, Advocatus, 2010, pp. 271-326.

26 Así lo dispone, en efecto, el artículo 119 del Código Penal Argentino.

27 Por ejemplo, la Constitución Argentina impone esta obligación entre las atribuciones del Congreso en los incisos 17 y 19 del artículo 75. 
JUAN M. MOCOROA

"pequeña" o, en especial, "víctima” importan un compromiso, no velado, respecto de la autoridad y prioridad del derecho estatal. Cuáles son los parámetros - los horizontes diría Taylor - que empleamos para deslindar esa identidad no es algo inocente. De tal modo, en el caso planteado, debemos determinar si esos horizontes serán endógenos a la comunidad de que se trata o si, por el contrario, qué es lo que puede contar en cuanto "práctica identitaria" debe ser realizado con las limitaciones heterónomas dispuestas por el derecho estatal. Si es lo primero, no existiría posibilidad de recurrir en procura de reclamos universalistas a una concepción de derechos individuales; si es lo segundo, la misma posibilidad de reclamos multiculturales fuertes carece de sentido. Pues, de algún modo, el reconocimiento de las culturas plurales y los márgenes de acción de las comunidades que las conforman, están limitados por aquello que el Estado en el que están enclavadas tolera que sea su identidad.

Pero, entonces, el interrogante que surge es cuál es el alcance de lo que Martín Farrel llama "las circunstancias del multiculturalismo". Estas se caracterizarían por dos propiedades: $i$ ) la gente pertenece a distintas culturas y ii) tienen interés en asegurar su continuación. ${ }^{28}$ Sin embargo, si los alcances de esa cultura son determinados de forma exógena — al margen de las interpretaciones de esa misma práctica realizadas por los grupos de que se trate-, no es posible sostener que exista un adecuado respeto de esa identidad. Si, por el contrario, ellos son determinados de un modo endógeno, no es posible conceptualmente considerar que existen limitaciones a su fijación.

De todos modos, me parece, el punto aquí es otro. No debe aceptarse cualquier propuesta institucional destinada a reconocer la relevancia, en sociedades plurales, de la diversidad cultural. En especial, cuando importa reconocer derechos diferenciados y especiales cuyos titulares serán determinados colectivos y determinan una prioridad axiológica sobre derechos individuales muy básicos. La tolerancia liberal no debe confundirse con el relativismo moral; ni implica que todas las culturas tengan el mismo valor ni la promoción

28 Farrell, Martín, “¿Hay derechos comunitarios?”, Doxa. Cuadernos de Filosofía del Derecho, núm. 17-18, 1995, p. 84. 
de instituciones basadas en una especie de anything goes. ${ }^{29}$ Entonces, debemos buscar una salida que justifique esta posición. Analizo, en la próxima sección, un intento en este sentido.

\section{UN INTENTO DE RESPUESTA: RAWLS Y LA JUSTICIA POLÍTICA}

Hasta aquí podríamos pensar que el liberalismo es incapaz de dar una respuesta coherente al reclamo de reconocimiento de las minorías culturales. Pero, ¿qué tan cierto es que la neutralidad y los derechos universales no puedan dar cuenta de la objeción multicultural y comunitaria? Al menos tal y como fue presentada en la sección anterior respecto a la "necesidad humana vital" del reconocimiento.

Para responder este interrogante, debiéramos precisar la noción de liberalismo. Eduardo Rivera López, por ejemplo, lo reconstruye en las siguientes tesis: $a$ ) una tesis metaética y $b$ ) un compromiso en el nivel sustantivo o normativo. De acuerdo a la primera, sería posible, a su vez, distinguir dos nuevas subtesis: i) tesis universalista: es posible justificar o fundamentar normas morales universales $-i$. $e$., poseen una validez que trasciende las diferentes concepciones del bien de tal o cual sociedad o individuo- y ii) tesis de neutralidad: es posible justificar normas morales neutrales respecto de las distintas concepciones del bien de un individuo o sociedad. ${ }^{30}$ En virtud de la segunda, se evidencia un compromiso con los derechos individuales, la tolerancia religiosa, la justicia distributiva, la autonomía individual, etcétera.

Ahora bien, la crítica comunitaria sostiene que 1) una norma moral sólo puede ser vinculante si, y en tanto y en cuanto, emana del marco comunitario al que pertenece un determinado individuo. En

29 En esta línea, Ernesto Garzón Valdez distingue cinco confusiones sobre la relevancia moral de la diversidad cultural -i. e., tolerancia como relativismo; diversidad cultural como enriquecimiento moral; identidad personal e identidad social; unidad cultural y unidad institucional; sujetos jurídicos y sujetos morales-. Cfr. "Cinco confusiones acerca de la relevancia moral de la diversidad cultural", en id., Instituciones suicidas. Estudios de ética y política, México, Paidós, 2000, pp. 199-240.

30 Cfr. Rivera López, Eduardo, "Las paradojas del comunitarismo", Doxa. Cuadernos de Filosofía del Derecho, núm. 17-18, 1995, pp. 97 y 98. 
JUAN M. MOCOROA

este sentido, su validez moral no puede extenderse de un modo universal, y 2) deben rechazarse los valores excesivamente individualistas. El liberalismo, por el contrario, abroquela el desarrollo comunitario y rechaza la dependencia de los individuos respecto de los grupos a los que pertenecen. Para el comunitarismo, esa pertenencia conforma las identidades particulares de cada uno. Además, sostienen, la tesis de la neutralidad es una pretensión imposible. ${ }^{31}$ La moralidad siempre aparece vinculada con una determinada concepción del bien.

Quizá sean estas objeciones las que llevaron a Rawls a la defensa de una interpretación más política de la teoría de la justicia liberal. ${ }^{32}$ Esta debería ser independiente de concepciones filosóficas, metafísicas y religiosas comprehensivas. De tal modo, la suya es una doctrina destinada a un ámbito específico de aplicación: la estructura básica de la sociedad -i. e., las principales instituciones políticas y económicas y el modo en que se articulan en un sistema unificado de cooperación social-. Por eso rechaza que se aplique a la conducta o a los ideales de vida de las personas. Ahora bien, no se trata de una teoría destinada a cualquier sociedad, sino que, por el contrario, sólo está destinada a una democracia constitucional. De ahí que recurre a las ideas intuitivas básicas arraigadas en las instituciones políticas de un régimen de este tipo y a las tradiciones públicas de su interpretación. Esto tiende a resolver un problema político práctico: lograr estabilidad. Ninguna concepción moral general ofrecería una base públicamente reconocida para sostenerse en un marco de pluralidad valorativa; no podría dar cabida a plurales y conflictivas concepciones del bien. Debe lograr autosostenerse, aun a pesar del "hecho del pluralismo" -i. e., en las democracias actuales existen diversas doctrinas vinculadas a concepciones del bien conflictivas e inconmensurables entre sí-. Para asegurar esto propone la aceptación de un overlapping consensus; caracterizado por un cierto nivel

31 Excelentes presentaciones de esta postura en MacIntyre, Alasdair, Tras la virtud, trad. de Amelia Valcárcel, Barcelona, Crítica, 1987; Sandel, Justicia, cit., y Democracy's Discontent. America in Search of a Public Philosophy, Cambridge, Harvard University Press, 1998, pp. 25-54.

32 Cfr. Rawls, John, "Justice as Fairness: Political not Metaphysical", Philosophy and Public Affairs, vol. 14, núm. 3, 1985, pp. 223-251, y El liberalismo político, cit. 
de generalidad que incluya a todas las doctrinas religiosas y filosóficas que normalmente se desarrollan en una democracia. Es, de tal modo, lo que podría llamarse una thin theory; se trata de un mínimo para facilitar el acuerdo de parte de visiones conflictivas. Así es posible que cada individuo se pueda adherir a una concepción pública de la justicia $-i$. e., tan independiente como sea posible de las doctrinas comprehensivas - sin que, por ello, deba abandonar su particular idea del bien. Entonces, se podrían resolver las divergencias de cooperación política con base en el respeto mutuo. Para que pueda lograr dicha finalidad esta idea debe cumplir ciertos recaudos: debe ser suficientemente profundo para abarcar la idea de que la sociedad es una empresa cooperativa equitativa y que las personas son libres e iguales, y amplio para incluir todas las cuestiones vinculadas a la estructura básica de la sociedad. ${ }^{33}$

En este sentido, una forma de comprender el overlapping consensus en una sociedad multiétnica, multicultural y multiconfesional es insistir en que los diferentes grupos preserven la autonomía de las personas, exclusivamente, en el ámbito público. No obstante, sería irrelevante que en las prácticas privadas aquellos grupos opriman a sus integrantes más débiles. ${ }^{34}$ Además, la concepción de Rawls se apoya sobre una concepción política de la persona -i. e., las personas son criaturas autónomas en el sentido de que en el nivel público deben ser tratadas como capaces de elaborar y buscar un sentido del bien y consagrarse a una cooperación razonable en torno de principio de justicia- ${ }^{35}$

De todos modos, me parece que la doctrina de Rawls es, pese a lo que declama, insuficientemente política. ${ }^{36}$ Relacionado con esto, podría objetarse la ambigüedad con que utiliza una noción que es central en su proyecto: "concepción política”. En rigor, este término es concebido como sinónimo de neutralidad. Esto es, su Justice as

33 Gargarella, Las teorías de la justicia después de Rawls, cit., pp. 198 y 199.

34 Cfr. Benhabib, Las reivindicaciones de la cultura, cit., p. 187.

35 Ibidem, p. 186.

36 Michael Sandel realiza una objeción independiente desde una concepción sustantiva. Para él, la posición de Rawls no puede dar cuenta del merecimiento, honor y virtud que la justicia compromete. Cfr. Sandel, Justicia, cit., pp. 190 y ss. 
JUAN M. MOCOROA

Fairness sería más política que concepciones alternativas porque sería más neutral que ellas. Ahora bien, no es una cuestión menor cómo se entienda este concepto sobre el que, a su vez, pueden existir desacuerdos razonables y profundos. Si se sostuviera que esto es correcto, puede ser el caso que no sería cierto que la suya sea una concepción (conceptualmente) política, sino, tan solo, neutral. Y, si esto es así, existirían dudas sobre la posibilidad del logro de su objetivo: desarrollar una concepción pública (y no comprehensiva) de la justicia. Para un comunitarista, por ejemplo, sería tan insoportablemente débil como para teorías liberales comprometidas fuertemente con la neutralidad estatal. ${ }^{37}$

Vinculado a esto, si es parte de una concepción política la existencia de desacuerdos sobre las distintas concepciones del bien y, por ende, entre las doctrinas que los respaldan, no veo por qué no podría ocurrir lo mismo respecto de los propios principios de justicia. Y, si esto es así, se advertiría el carácter de insuficientemente político (neutral) al que me refiero. Es que asumir, lo que Waldron llama "circunstancias de la política" y, por tanto, pretender cierta autonomía para la política respecto de concepciones filosóficas comprehensivas - como es la intención de Rawls - invita a aceptar que, también, los desacuerdos deberían presentarse tanto en el nivel concreto de las concepciones comprehensivas de que se trate, como en el más general de la determinación de los principios de justicia. ${ }^{38}$ Si esta objeción fuera correcta, tampoco podría ser una réplica sostener que, en virtud del consenso superpuesto, se espera de los ciudadanos que recurran en el debate democrático a razones públicamente aceptables y que ellas, en rigor, debieran ser políticas (neutrales) respecto de sus concepciones comprehensivas del bien. Es que, me parece, podría ser correcto exigir esto de las instituciones -i. e., de la estructura básica de la sociedad-, sin embargo no parece correcto que esto se les exija a los ciudadanos; en tanto es en virtud de esto que doctrinas diferentes pueden afirmar una base públicamente compartida de las instituciones políticas. Como dice

37 Cfr. Ovejero, Félix et al., "Introducción", en id. (eds.), Nuevas ideas republicanas. Autogobierno y libertad, Barcelona, Paidós, 2004, p. 24.

38 Véase Waldron, Derecho y desacuerdos, cit., pp. 177 y ss. 
Gargarella, parecería que - en virtud de la idea de razón publicase les exige a esos ciudadanos que pongan entre "paréntesis" sus creencias éticas más profundas. ${ }^{39}$

A mi criterio esta última cuestión ni es practicable realmente ni es deseable en términos normativos. Lo primero, porque resulta notablemente complejo requerir de los individuos que desdoblen sus creencias al momento de participar políticamente. Lo segundo, porque un debate democrático, público y robusto, exige que los ciudadanos no sean ni hipócritas ni cínicos; sino que, antes bien, pretendemos de ellos que se comporten fidedignos respecto de cuáles son sus creencias sobre cómo es posible delinear un vivir en común.

Por supuesto, pueden matizarse estas objeciones del siguiente modo. Lo único que exigiría la teoría sería que los ciudadanos intenten convencer a sus congéneres y el único modo razonable en que podrían lograr éxito en esa empresa es que maticen sus propias posiciones más radicales para que ellas puedan ser aceptadas por los otros con los que deben deliberar. Ahora, si esta es la tarea, dista mucho de tratarse de una especie de razón pública con un componente moral, sino que sólo se limita a una exhortación instrumental para lograr un acuerdo falible y sostenible en el tiempo entre los ciudadanos de una democracia constitucional.

Entonces, si el principal problema a encarar consiste en lograr unidad social cuando no puede alcanzarse un acuerdo público sobre una única idea del bien, dado el hecho del desacuerdo, debería ofrecer razones independientes - si es que existen - sobre por qué este conflicto se daría en un nivel y no en el otro. Justice as Fairness, para solucionar esto, se basa en un conjunto de principios públicamente aceptables que regulan la estructura básica de la sociedad —entendida como sistema de cooperación entre personas libres e iguales que genera condiciones de lealtad-. El interrogante que subyace es: ¿cómo es posible que exista una sociedad estable y justa de ciudadanos libres e iguales profundamente dividida por doctrinas religiosas, filosóficas razonables, pero incompatibles entre sí? Ahora bien, si ella se basa en una descripción de las condiciones subyacentes a sociedades plurales no podría, coherentemente, sostener

39 Cfr. Gargarella, Las teorías de la justicia después de Rawls, cit., p. 207. 
que los desacuerdos razonables sólo tienen lugar en el ámbito de las concepciones del bien particular de que se trate y condenar los desacuerdos más abstractos y profundos sobre los propios principios de justicia, como irrazonables por definición. Y, de este modo, no podría dar una respuesta adecuada al problema con el que se enfrenta.

Entonces, si parece insuficientemente política esta doctrina para hacer frente a este tipo de desacuerdos, deberíamos pensar en una concepción alternativa que pueda brindarnos poderosas razones para afrontar este tipo de disensos. Más allá de eso, es necesario, todavía, ahondar un poco más respecto del reclamo de reconocimiento. A tal fin, en lo que sigue, me ocuparé de la posición de Charles Taylor.

\section{LA NECESIDAD DEL RECONOCIMIENTO Y LA POSICIÓN DE CHARLES TAYLOR}

"La política del reconocimiento" de Charles Taylor es, por diversos motivos, especialmente provocadora. ${ }^{40}$ En particular, dado su profundo enfoque filosófico e histórico. Además, cuestiona nociones básicas en el ámbito de los derechos humanos y pone en duda intuiciones muy extendidas en ese dominio. En particular, su carácter abstracto y su universalidad. A partir de su discurso, parecería que el universalismo de los derechos invisibiliza las diferencias y, con eso, no logra su objetivo de proteger de un modo adecuado a las minorías, en particular, las culturales.

Para Taylor, abstracción y universalidad no es algo digno de encomio sino que, al contrario, un serio déficit. Como sostuviera Habermas, la cuestión aquí es si una teoría de los derechos individualista puede hacer justicia a la lucha por reconocimiento de las minorías culturales sin, por eso, negar de su identidad colectiva. ${ }^{41}$ Para el liberalismo, por supuesto, no existe inconveniente alguno. Aceptado

40 Cfr. Taylor, "La política del reconocimiento", cit., pp. 53-116.

41 Cfr. Habermas, Jürgen, "La lucha por el reconocimiento en el Estado democrático de derecho", en Taylor, Charles, El multiculturalismo y "la política del reconocimiento", 2a. ed., trad. de Mónica Utrilla de Neira et al., México, Fondo de Cultura Económica, 2009, p. 156. 
esto, el interrogante se invierte: ¿pueden protegerse los derechos individuales si se enfatiza la afirmación de la identidad colectiva? En casos de conflicto, ¿es tolerable que los derechos (liberales) más básicos sean derrotables por consideraciones referidas a la identidad colectiva de grupos culturales minoritarios? Anudado a esto, ¿debe abandonarse la neutralidad para lograr este reconocimiento?

Según Walzer, Taylor propone una versión particular del liberalismo (a la que llamó "Liberalismo 2"). ${ }^{42}$ Esta interpretación permitiría un Estado comprometido con la supervivencia y el florecimiento de una nación, cultura o religión en particular. Sin embargo, lo hace sujeto a una condición: asegurar el debido respeto a los derechos más básicos de los ciudadanos. ${ }^{43}$ Este liberalismo se opondría a otras posiciones que se apoyan sobre: $i$ ) una vigorosa defensa de los derechos individuales, y ii) un Estado rigurosamente neutral. Según esta posición, hacer compatibles nuestras intuiciones morales más básicas con una noción robusta de derechos humanos, rechaza que ellos sean derrotados en pos del aseguramiento de afirmaciones identitarias de índole colectiva.

Ahora bien, esta posición o es trivial o no puede aceptarse. Es trivial si el reconocimiento de la identidad colectiva debe efectuarse en pos de asegurar, siempre, los derechos individuales de los miembros de los grupos de que se trate. Dado que, si esto es así, no se trata, en rigor, de una verdadera alternativa al liberalismo igualitario; dado que sus presupuestos pueden dar cuenta de estas intuiciones. El caso de Rawls, y su propuesta de una teoría política de la justicia, es palmario en este sentido. No puede aceptarse si importa dejar de lado derechos individuales básicos de corte universal. Porque, de lo contrario, afectaría nuestras intuiciones más elementales sobre qué implica respetar aquellos derechos. Mi crítica puede hacerse, en este sentido, más general. Para que una posición sea coherentemente defensora de los derechos colectivos de ciertas minorías culturales debe-

42 Cfr. Walzer, Michael, “Comentario", en Taylor, Charles, El multiculturalismo y 'la política del reconocimiento'”, cit., p. 147.

43 Ibidem, p. 146 ("en la medida en la que los derechos básicos de los ciudadanos que tienen diferentes compromisos, o que no los tienen en absoluto, estén protegidos"). 
rían poseer una especie de jerarquía superior sobre los derechos individuales. Si bien es un lugar común afirmar que en estos términos los conflictos de derechos ni son tan profundos ni están tan extendidos, desde un punto de vista teórico y político la pregunta se mantiene. ¿Cómo debe afrontar una comunidad política las reivindicaciones culturales que importan una afrenta a la conciencia moral más básica desde un punto de vista universalista? Este interrogante se profundiza si pensamos en que esas reivindicaciones culturales pueden ser parte de la conformación identitaria de un colectivo.

Además, me parece, podría reprochársele a Taylor cierto utopismo: él sólo piensa en condiciones positivas de este reconocimiento identitario. Pero no destaca los latentes peligros y perjuicios presentes. En especial, dado que identifica la identidad de los ciudadanos de un modo desvinculado de cuáles pueden ser sus consecuencias. Pienso, por ejemplo, en algunos estudios de Amartya Sen en los que argumenta sobre el vínculo estrecho entre identidad y violencia. En efecto, destaca cierta paradoja en la identidad: es, al mismo tiempo, un principio de inclusión y de exclusión. ${ }^{44}$

Por otro lado, parecería que su propio discurso no ofrece guías para establecer criterios adecuados que impongan límites a la identidad y reconocimiento. Me refiero a lo siguiente: es posible que la necesidad del reconocimiento provenga de la pertenencia a una minoría cultural determinada; pero qué ocurre, por ejemplo, con las minorías al interior de ese propio grupo. Más aun cuando estas minorías de segundo orden, también podrían reclamar reconocimiento dentro de ese mismo grupo (de primer orden). ${ }^{45}$ El problema parece dilemático, si se hace eco de ambos reclamos, colapsa el reclamo más amplio de reconocimiento de la minoría de primer orden que puede consistir casualmente en cierta posición que deben ocupar las minorías de segundo orden dentro de ese colectivo. Pero, además, si sólo recoge uno de esos reclamos, la teoría sería insuficiente-

44 Sen, Identidad y violencia, cit., p. 25 ("el sentido de equidad puede excluir, de modo inflexible, a mucha gente mientras abraza cálidamente a otra").

45 Sobre este problema, véase Okin, Susan M., Is Multiculturalism Bad for Women?, Princeton University Press, 1999 (respecto de las mujeres y el multiculturalismo). 
mente abarcadora; ya que no brindaría respeto a todos los reclamos de reconocimiento sino que lo haría de modo parcial. Entonces, debería ser rechazada por contradictoria. Todo esto nos coloca frente a los problemas que Lukes identificó respecto del comunitarismo: i) inclusión/exclusión; ii) relativismo, y, por último, iii) la desviación. Vale decir, no existen criterios claros y suficientemente aceptables acerca de cómo decidir qué comunidades se incluyen en las estructuras globales y cuáles no; nos puede obligar a permitir prácticas repugnantes que afectarían nuestros esquemas conceptuales más básicos sobre la moralidad y el tratamiento que merecen los individuos en pos de asegurar su autonomía, y, finalmente, no todos los integrantes de los colectivos que se señalan como relevantes, encajan bien en la comunidad definida en términos globales. ${ }^{46}$

Dadas estas insatisfacciones, debiéramos buscar una filosofía política alternativa que brinde las respuestas (políticas) que estamos buscando y que impida que incurramos en algunos excesos que no compartiríamos. Además deberá respetar la identidad colectiva e individual. Una opción interesante, a mi criterio, es el republicanismo. En el próximo apartado, analizo esta posición.

\section{DELIBERACIÓN POLÍTICA, REPUBLICANISMO Y HETEROGENEIDAD CULTURAL}

Como dije, los vínculos identitarios pueden generar exclusión. Por eso, $i$ ) deben someterse a un procedimiento y ii) no es deseable concebirlos como no controvertidos o dados desde afuera $-i$. e., su aceptación sea una imposición externa al margen de las creencias y convicciones del sujeto de que se trate- Al contrario, deben tomarse como preferencias moldeadas políticamente; modificables, entonces, en el seno de un debate colectivo y democrático.

Los seres humanos deben pensarse desde un punto de vista multidimensional y no como "criaturas unidimensionales". ${ }^{47}$ Aquí anida

46 Lukes, Seteven, "Cinco fábulas sobre los derechos humanos", en Shute, Stephen y Hurley, Susan (eds.), De los derechos humanos. Las conferencias Oxford Amnesty de 1993, Madrid, Trotta, pp. 29-46.

47 Ibidem, p. 231. 
un problema de algunas visiones multiculturales. En efecto, tienden a i) ignorar toda filiación y toda lealtad distinta de la que emana de una identidad restrictiva; ii) puede ser profundamente engañosa; y, también, iii) contribuir a la tensión y a la violencia social. ${ }^{48}$ Una respuesta institucional alternativa a este enfoque monocausal de la identidad - en rigor, no pública-, debiera poder dar cauce i) tanto a la exclusión de situaciones de dominación de los individuos - ya sea intra o intergrupales-, como a ii) la posibilidad de controvertir las identidades héteroimpuestas a los individuos. En virtud de i), entonces, deberían excluirse las acciones que impongan condiciones de dominación respecto sobre los individuos - ya sea que provengan del Estado o de las propias minorías culturales-. Mientras que, según ii), no son toleradas las reducciones identitarias en las que pueden ser colocados ciertos individuos, sin el consentimiento expreso o razonablemente implícito de quien se vería beneficiado por ellas -i. e., se trate de un ejercicio de autonomía pública o privada en términos de Habermas-.

El republicanismo, intuyo, podría dar la respuesta suficientemente política que estamos buscando. Además, podría dar razones para requerir fuertes lealtades constitucionales, virtudes cívicas extendidas y, fundamentalmente, excluir condiciones de dominación, sin importar su origen, causa o sujeto que las genere - público o privado-.

\section{El republicanismo según Pettit: en búsqueda de la no dominación}

Para Phillip Pettit, el republicanismo es una filosofía social anticolectivista y antiatomista. ${ }^{49}$ Está en contra, entonces, del puro mayoritarismo y de cierto liberalismo (en particular, el libertarianismo). Pueden identificarse las siguientes premisas de su razonamiento: 1) una democracia fuerte (vinculada a presupuestos deliberativistas); 2) compromiso con ciertas virtudes cívicas (para contrarrestar la apatía política y asegurar condiciones de no domi-

48 Ibidem, p. 46.

49 Pettit, Philip, Republicanismo. Una teoría sobre la libertad y el gobierno, trad. de Antoni Doménech, Barcelona, Paidós, 1999. 
¿SOMOS PRISIONEROS DE NUESTRA IDENTIDAD?

nación y libertad), y 3) una concepción de la libertad como no dominación. ${ }^{50}$

Este último aspecto es la característica dirimente para Pettit. Se trata de un estatus social de estar a salvo de la interferencia arbitraria de otros y de ser capaz de disfrutar de un sentido de seguridad. Su finalidad, entonces, es excluir condiciones de dominación en el que la parte dominante pueda interferir en las elecciones de la parte dominada a partir de un interés u opinión no necesariamente compartidas por la persona afectada (realizadas con arbitrio e impunidad). Como dice este autor: "...La dominación puede ocurrir sin interferencia, porque solo requiere que alguien tenga capacidad para interferir arbitrariamente en mis asuntos; no es necesario que nadie lo haga realmente" ${ }^{51}$ Es por eso que puede dar cuenta de casos intuitivos de falta de libertad en las que existe dominación, aun cuando no exista interferencia actual sobre el dominado. ${ }^{52}$

Para que exista dominación, por otra parte, requiere de tres condiciones: 1) el agente (que puede ser colectivo) tiene capacidad real para interferir en las opciones o acciones de otro - i. e., las modifica; altera los beneficios esperados; controla los resultados y ejerce coer-

50 Sobre esto, véase Ovejero et al., "Introducción”, cit., pp. 18 y 31.

51 Cfr. Pettit, Republicanismo, cit., p. 42.

52 Esto distinguiría claramente la libertad republicana con la sostenida por el liberalismo: negativa o como ausencia de interferencia. Para esta doctrina, para que esté comprometida la libertad debe existir necesariamente interferencia. Para el republicanismo, al contrario, aun cuando no exista interferencia actual un sujeto puede ser dominado por otro dado que estaría en condiciones de interferir arbitrariamente sobre sus cursos de acción cuando lo desee. Para advertir su potencial antidominador, piénsese en el siguiente ejemplo. En el caso de un matrimonio musulmán, que vive en un Estado islámico, los derechos de la mujer están limitados a tal punto en que ella está sometida a la voluntad de su marido. Aun cuando él sea benevolente y no interfiera en su contra. Según una concepción negativa de la libertad, la falta de interferencia actual, determina una situación de libertad. Para el republicanismo, que la estructura jurídica garantice la posibilidad de interferir arbitrariamente, es suficiente para reconocer la situación de dominación. Sobre este ejemplo, Ovejero et al., "Introducción”, cit., pp. 21 y 22. Para el análisis del concepto de libertad "negativa” y "positiva”, véase Berlin, Isaiah, "Dos conceptos de libertad", en id., Sobre la libertad, Henry Hardy (ed.), trad. de Julio Bayón et al., Madrid, Alianza, 2009, pp. 206-255, en especial, pp. 208-217. 
JUAN M. MOCOROA

ción física, manipulación, etcétera, en suma, genera un impedimento intencional一; 2) arbitrariamente (está sujeto al juicio de otro sin atender los intereses u opiniones del afectado), y 3) en determinadas elecciones que otro puede realizar. En suma, como dice Pettit:

[e]sta concepción de la libertad es socialmente exigente, en la medida en que significa que la dependencia de la buena voluntad de otro - tener que vivir a merced de otro- es contraria a la libertad. Incluso si el otro en cuestión - el dominus - es perfectamente feliz dejando a la persona hacer lo que quiera, el propio hecho de la dependencia y la vulnerabilidad, de la posibilidad para ese dominus de ejercer una interferencia arbitraria, significa que la persona no es libre. Todo lo que haga lo hace por permiso implícito del dominus. ${ }^{53}$

La filosofía política republicana, entonces, sostiene una posición "socialmente radical", en tanto impone al Estado establecer un orden social en que los ciudadanos gocen de independencia frente al poder arbitrario de otros. De ahí que la autoridad política deba ser concebida como "potencialmente dominadora". Y, por eso, debe ser restringida por una Constitución. Esta Constitución, al menos, debería garantizar: i) mecanismos adecuados de representación; ii) la rotación de los cargos; iii) separación de poderes; iv) bicameralismo; v) federalismo, y vi) judicial review. ${ }^{54}$ Además, vii) debe asegurarse la protección de un conjunto de derechos individuales. Esta estructura básica debería satisfacer los intereses comunes de los ciudadanos.

53 Cfr. Pettit, Republicanismo, cit., p. 43.

54 De todos modos, determinar el contenido concreto de esta Constitución no es una cuestión pacífica entre los autores autocalificados "republicanos". En particular, puede verse la discusión respecto de la necesidad de constitucionalizar el judicial review. Para Bellamy, por caso, esta institución desprovista de instancias por las que la mayoría de la población pueda desvincularse de los productos judiciales de ejercicio del control de constitucionalidad es, en sí misma, dominadora. Por eso, califica la posición de Pettit como una "estrategia despolitizadora" -i. e., se basa en una política idealizada sin considerar las fuentes de los desacuerdos razonables-. Cfr. Bellamy, Richard, Constitucionalismo político. Una defensa republicana de la democracia, trad. de Jorge Urdánoz Ganuza y Santiago Gallego Aldaz, Madrid, Marcial Pons, 2010. Véase, también, Tomkins, Adam, Our Republican Constitution, Oxford, Hart, 2005. 
Al mismo tiempo, insiste Pettit, debe garantizar un fuerte ideal de "discriminación constitucional". Según éste, el Estado está obligado a respetar los intereses percibidos de los ciudadanos en su manera de interferir no dominadora. Es así que tenderá al establecimiento del control cívico sobre el gobierno. Las Constituciones, de esta manera, minimizan la dominación del Estado. ${ }^{55}$

La vinculación entre la libertad como no dominación y el constitucionalismo, entonces, es conceptual. Para el republicanismo tiene el valor de permitir que la gente sepa que no viven a merced de los funcionario públicos y excluyen $i$ ) el dominium -i.e., poder arbitrario de los sujetos privados-, y ii) el imperium -i. e., poder arbitrario del poder público-. De ahí que se sirva de normas cívicas sustantivas y de la exigencia de cierto cúmulo de virtudes. Además, el gobierno debe ser expresión igualitaria de preocupaciones comunes. Las iniciativas del gobierno, entonces, debieran estar sujetas al control popular y los ciudadanos disfrutar de suficiente poder para ejercerlo. El gobierno, entonces, debe ser dirigido por la expresión igualitaria de las preocupaciones comunes, nunca por intereses sectoriales. Esto garantizaría, para Pettit, que sea $i$ ) democrático en el sentido etimológico del término -i. e., gobierno del demos-; ii) la ciudadanía ejerza un efectivo e igual control sobre el gobierno, y iii) rechaza el despotismo electivo, dado que ese control inmuniza a las minorías de la imposición de la voluntad mayoritaria ilimitada. Finalmente, opera bajo una Constitución mixta en un contexto de vigilancia ciudadana (contestatory citizenry). En suma, el republicanismo intenta que la autoridad final sobre los temas de relevancia pública no recaiga en un único centro ilimitado de poder —incluso si este es el pueblo considerado como un todo-.

Finalmente, tiene una relación muy estrecha con la idea de rule of law. En tanto dificulta la manipulabilidad de parte de los aplicadores de la ley, intenta, en fin, instaurar gobierno de la ley, no de los hombres. ${ }^{56}$ Es que "si se rompe la constricción del imperio de la ley,

55 Estos mecanismos institucionales, sin embargo, se asemejan de un modo notable a las propuestas, y a los diseños institucionales, justificados por autores liberales. Destacan este punto Ovejero et al., "Introducción”, cit., p. 36.

56 Pettit, "La libertad republicana y su trascendencia constitucional”, cit., p. 49. 
entonces la ley se convierte en campo abonado para la voluntad arbitraria de las autoridades". A fin de evitar esta posibilidad de manipulación, y por tanto la creación de "circunstancias de dominación", el republicanismo se compromete con una visión particular de cómo deben ser esas "leyes". Exige que sean generales en su contenido, de aplicación universal, no retroactivas, inteligibles, consistentes y que gocen de cierta estabilidad..$^{57} \mathrm{El}$ punto es evitar que tanto ejecutores como aplicadores estén en condiciones de ejecutarlas o aplicarlas en sentido contrario al interés común y confieran poderes arbitrarios sobre los ciudadanos. No obstante, no fetichiza el principio de legalidad; acepta que podrían darse circunstancias en las que un margen de discrecionalidad fuera necesario.

A mi criterio, el ideal de no dominación es necesario para la satisfacción de mejores condiciones de autogobierno. Aunque no creo que sea consistente Pettit cuando lo desvincula casi absolutamente de la participación política de la ciudadanía. Tengo la impresión que debería ser más mayoritario que el marco presentado por este autor. En particular, no veo cómo políticamente podría ser un ideal atractivo si no se lo vincula la con participación política para el mantenimiento de una sociedad libre. Al contrario, la no dominación requiere (y exige) esa participación de los afectados por las decisiones que les conciernen; como una cuestión sustantiva y no como un medio para asegurar otros valores.

\section{Republicanismo, estabilidad y virtudes cívicas}

Para la estabilidad y calidad de la democracia es necesario y deseable que los ciudadanos gocen de un conjunto de virtudes cívicas. Es que " $[\mathrm{u}]$ na república que se autogobierna solo puede perdurar... si sus ciudadanos cultivan esa cualidad decisiva a la cual Cicerón denominó virtus, los teóricos italianos más tarde convirtieron en virtù y los republicanos ingleses tradujeron como civic virtue o public-spiritedness (virtud cívica o vocación publica)". Se trata de las “capacip. 50 .

${ }^{57}$ Cfr. Pettit, "La libertad republicana y su trascendencia constitucional", cit., 
dades que nos permiten por voluntad propia servir al bien común, y de este modo defender la libertad de nuestra comunidad para, en consecuencia, asegurar el camino hacia la grandeza, así como nuestra propia libertad individual". ${ }^{58}$ A no dudarlo, una democracia de ciudadanos apáticos, poco informados y no comprometidos con la cosa pública, tiene el peligro de generar situaciones de dominación.

La res publica implica un sistema político en el que no existe un gobierno de unas personas sobre otras sino que, antes bien, se funda en una profunda igualdad ciudadana gobernada por el rule of law; se trata, entonces, del gobierno de las leyes, no de los hombres. Y esto porque la libertad implica la ausencia de condiciones de dominación impuestas ya sea por el gobierno, ya sea por grupos poderosos de particulares. La vinculación de estos objetivos con cierto conjunto de virtudes cívicas es estrecha. Se trata, en suma, de rechazar al ciudadano consumidor. ${ }^{59}$

Entonces, una democracia asentada sobre un conjunto marcado de virtudes cívicas favorece tanto su estabilidad como su calidad. Ambas cuestiones son posibles gracias a que tienen un fundamento común: los ciudadanos son los mejores protectores de su propia libertad. Sólo "buenos ciudadanos" pueden llevar a cabo una tarea y actividad que es requerida para garantizar la cosa pública; un compromiso vigilante para sostener y apoyar al Estado y protegerse de su dominación. Subyace a esto una diferencia con el liberalismo. Para el republicanismo los gobernantes no son necesariamente "corruptos", agentes de los que la ciudadanía debe defenderse. Al contrario, su consideración antropológica es que ellos son, en todo caso, "corruptibles". Este matiz importante justifica una actitud constante de vigilancia sobre su accionar. Por eso, no se trata de sostener, como dice Pettit, que los ciudadanos deben ser virtuosos para participar en política sino que se promueve su compromiso con estas virtudes para evitar el peligro de la "corrupción". ${ }^{60}$ A partir de ellas, asumen

58 Skinner, Quentin, "Las paradojas de la libertad política”, trad. de Verónica Lafrieri, en Ovejero et al. (eds.), Nuevas ideas republicanas, cit., p. 106.

59 Sobre esto y su vínculo con la noción de "mercado", por oposición a la de "foro" o "esfera pública", véase Dagger, Richard, Civic virtues, Oxford, Oxford University Press, 1997, pp. 104 y ss.

60 Es por eso que Pettit las llame civic minded dispositions. Adviértase que, para 
JUAN M. MOCOROA

un compromiso con los demás miembros de la república en la persecución del bien común y no sólo consigo mismos. Así, aseguran una mayor obediencia y respeto a las leyes; éstas atienden mejor sus intereses; los ciudadanos actúan como preocupados custodios de que nadie se desvía del cumplimiento de la ley. Advierten que son parte de un proyecto común y que la única manera de no ser dominados es proteger el bien común. Estas virtudes cívicas, por fin, hacen a los ciudadanos conscientes de que son parte en una empresa continua que necesita su cooperación.

La finalidad última es la generación de condiciones para el rechazo de una ciudadanía mercantil y el apoyo a una ciudadanía política; que sus miembros estén "comprometidos con los asuntos públicos de su comunidad y no simplemente como titulares de derechos y clientes acreedores a ciertas prestaciones" ${ }^{61} \mathrm{Y}$ esto se relaciona de un modo estrecho con la calidad de la democracia; la ampliación de la esfera pública y la participación ciudadana, sin dudas, la mejora.

A partir de esto, pienso, podríamos identificar algunas virtudes que son relevantes en términos políticos. Debería tratarse, en todos los casos, de disposiciones importantes para el desarrollo de las condiciones necesarias para que los ciudadanos puedan reconocerse como partícipes de una comunidad generando condiciones de autogobierno y libertad. Además, a partir de ellas, deberían efectivizar y materializar uno de los objetivos que el republicanismo tiene en cuenta al exigirlas: una ciudadanía vigilante del gobierno preocupada por los destinos de su comunidad intentando ahuyentar la "corrupción”, siempre latente. Todas, además, deberían vincularse de un modo estrecho con la ampliación y el mejoramiento de la "esfera pública” en el que ellas deben ejercerse; de ahí su impronta propiamente política. A saber: lealtad - i. e., a la comunidad con la que los ciudadanos están comprometidos y en la que deben desarrollar es-

el republicanismo clásico, la corrupción no sólo implicaba atender a los propios intereses sino, y lo que es más fundamental, una falla de racionalidad -i. e., una incapacidad para reconocer que la libertad depende del compromiso con una vida de virtud y servicio público-. Cfr. Skinner, "Las paradojas de la libertad política", cit., p. 108, y Dagger, Civic virtues, cit., p. 105.

61 Peña, Javier, “Ciudadanía republicana y virtud cívica”, en Bertomeu, María Julia et al., Republicanismo y democracia, cit., p. 232. 
tas virtudes: destinada a evitar situaciones de corrupción en función de la responsabilidad que implica la participación con otros en la búsqueda del interés común-, patriotismo constitucional, obediencia y respeto a la ley; empatía -i. e., intentan asumir la posición de quienes están en desacuerdo con ellos- ${ }^{62}$ y participación política, ${ }^{63}$ responsabilidad ciudadana y prudencia (phronesis) - i.e., la capacidad de deliberar y resolver racionalmente los fines esenciales de la vida humana-.

Ahora bien, existen algunas virtudes que carecerían de relevancia alguna en términos políticos y que, sin embargo, son consideradas esenciales por algunas posiciones que reivindican derechos diferenciados por algunas minorías culturales. Éstas, en rigor, ni se refieren ni se vinculan de un modo mediato o inmediato con la esfera pública; por tanto, no son necesarias para la deliberación política y la disputabilidad al gobierno. Son valores, en este sentido, privados. Por ejemplo, la fe y las creencias religiosas, la caridad, la sabiduría, la modestia. El republicanismo, entonces, asume una exigente concepción de la ciudadanía.

Esto, en rigor, no implica renunciar al principio de neutralidad estatal ni sostener una concepción perfeccionista -i. e., imposición de ideales de excelencia personal-. Sin embargo, quizá, por miedo a adoptar estas posiciones, la cuestión de las virtudes "parece estar fuera de lugar en el discurso político". ${ }^{64}$ Es más, como se ha sostenido, parece que fueran o peligrosas o innecesarias. ${ }^{65}$ Lo segundo, porque las instituciones de la democracia estarían en condiciones de suplir la escasa virtud de los ciudadanos. Lo primero, porque podría ser el caso que se trate de la imposición despótica de la visión de una minoría ilustrada. Por ejemplo, un autor liberal como Carlos Nino pensaba que debían rechazarse las justificaciones perfeccionistas de la democracia que buscaran fortalecer virtudes de carácter

62 Cfr. Sunstein, Cass, "Más allá del surgimiento republicano", trad. de Verónica Lafrieri, en Ovejero et al. (eds.), Nuevas ideas republicanas, cit., p. 159.

63 Según la cual los actores políticos, en una situación de deliberación, "intentan asumir la posición de quienes están en desacuerdo". Cfr. Sunstein, "Más allá del surgimiento republicano", cit., p. 159.

64 Peña, “Ciudadanía republicana y virtud cívica”, cit., p. 232.

65 Idem. 
JUAN M. MOCOROA

y satisfacer ideales de excelencia humana; siempre que tendieran a promover el interés ciudadano por la cosa pública, generar actitudes de solidaridad, fomentar disposiciones igualitarias, fortalecer el autorrespeto y afirmar la individualidad. En tanto, si la vemos como un medio para promover esas virtudes se da la prelación de una cierta forma de vida por sobre otra; lo que no toleraría una concepción liberal asentada sobre el principio de autonomía e inviolabilidad de las personas. ${ }^{66}$

Más allá de esto, creo que es posible distinguir dos justificaciones distintas respecto de la vinculación de la democracia, ciudadanos y virtudes cívicas. Lo que tiene una importancia fundamental para establecer el rango de acción por parte del Estado y, además, para dar una respuesta a aquellos planteamientos. Por un lado, una justificación instrumental y, por otro, una sustantiva. ${ }^{67}$ Según la ciudadanía activa sea requerida porque es algo bueno en sí misma o porque es una forma para contribuir a la preservación de una sociedad libre. ${ }^{68}$ El vínculo entre estas justificaciones diferencia a quienes, no obstante ser cercanos al republicanismo, defienden elementos comunitaristas en sus planteamientos. De este modo, la diferencia fundamental está dada por el compromiso con un principio muy caro al liberalismo político: la neutralidad del Estado. La estrategia sustantivista reposa, antes que nada, sobre aspectos aristotélico-comunitarios y no en la neutralidad. Entonces, requiere que los ciudadanos sean "buenos ciudadanos" pero, además, la considera una cuestión de carácter, y, si esto es así, requiere transformarlos e imponer una concepción específica del bien que defienda las virtudes cívicas como su contenido.

Según la versión instrumental, al contrario, las virtudes cívicas son exigidas en el ámbito público para conformar buenos ciuda-

66 Cfr. Nino, Carlos S., Fundamentos de derecho constitucional. Análisis filosófico, jurídico y politológico de la práctica constitucional, Buenos Aires, Astrea, 2002, p. 199.

67 Sobre el vínculo entre virtudes y republicanismo, analizado como sustantivo e instrumental, véase Dagger, Civic virtues, cit.; Patten, Allan, "La crítica republicana al liberalismo", trad. de Sandra Girón, en Ovejero, Martí y Gargarella, Roberto (eds.), Nuevas ideas republicanas, cit., y Peña, "Ciudadanía republicana y virtud cívica”, cit., pp. 248 y ss.

${ }^{68}$ Cfr. Patten, “La crítica republicana al liberalismo”, cit., p. 237. 
danos y no intenta transformar su carácter. Es instrumental en el sentido de que las valora en función de su capacidad para asegurar condiciones de no dominación y una ampliación de la esfera pública para mantener bajo control al gobierno y excluir cualquier posibilidad de corrupción. Para este criterio, aseguran que el ciudadano participe de la cosa pública, controle al gobierno y dispute sus decisiones exigiendo razones para imponerlas. De ahí que existe un vínculo conceptual entre una buena ciudadanía y el compromiso con una actitud vigilante y controlante sobre el Estado para evitar esas situaciones. Si los requerimientos estatales no se basan en la necesidad de imponer ideales de excelencia humana sino que, antes bien, están destinados a promover instrumentalmente la libertad de los ciudadanos, debería ser tolerado también por liberales igualitarios. ${ }^{69}$ En este sentido, nótese, determinar si se impone una concepción del bien no es independiente de "por qué se promuev[e] un determinado concepto de la virtud cívica". ${ }^{70}$ Y ello se relaciona con su fundamentación: instrumental o sustantiva.

Como dije, el Estado tiene un amplio rango de acciones para favorecer estas virtudes y, con ello, la libertad en sentido republicano. Sólo requiere una vinculación estrecha del individuo con su comunidad, y no, por el contrario, establecer una fusión entre lo particular y lo público o alentar una imposición totalitaria de la colectividad. Por eso, el ciudadano posee ciertos deberes de civismo que se relacionan con su compromiso respecto del bien común y con la salud democrática de su comunidad. ${ }^{71}$ El límite sobre lo que puede imponer el Estado, entonces, está dado por el interés en los asuntos de interés público y el bien común.

69 Para una posición cercana, Nino, Fundamentos de derecho constitucional, cit., p. 200 ("no es misión del Estado abrazarlo como válido sino en la medida que sea instrumentalmente necesario para el buen funcionamiento de las instituciones democráticas").

70 Kymlicka, Will, "Igualitarismo liberal y republicanismo cívico: ¿amigos o enemigos?”, trad. de Tomás Fernández Aúz, en Ovejero et al. (eds.), Nuevas ideas republicanas, cit., p. 215.

71 Sobre esto, Martí, José L., La república deliberativa. Una teoría de la democracia, Madrid, Marcial Pons, 2004, p. 250. 
JUAN M. MOCOROA

\section{Un deber cívico necesario: el voto}

En este orden de ideas, creo que es aceptable y justificable desde un punto de vista republicano que el voto sea obligatorio. Pero aquí, otra vez, existe un solapamiento con algunas respuestas que podría dar cierto liberalismo igualitario. Pienso que pueden darse dos respuestas positivas; una liberal y otra republicana. El libertarismo, al contrario, sostendría que en cualquier caso es una violación a la libertad.

Más allá de esto, una posición liberal podría pensar que debería ser obligatorio porque es una forma de aumentar la autonomía de ciertos individuos. Paradójicamente, un modo de asegurar la selección de planes de vida sería, en este caso, adoptar medidas relativas a un paternalismo jurídico legítimo que tiendan a facilitar las condiciones necesarias para la selección de los planes de vida de que se trate. ${ }^{72}$ Esta visión está sujeta a objeciones internas sobre, por ejemplo, si es cierto que se trata de favorecer la autonomía y, además, si es un medio adecuado para ello.

Sin embargo, a mi criterio, la justificación republicana es más coherente y consistente. Sostiene, por un lado, que un sistema de elecciones abiertas es un bien público. Y, si esto es así, estamos ante posibles y frecuentes problemas de coordinación sobre la participación en política; podría darse un verdadero dilema de los prisioneros. Y, entonces, sólo una intervención externa evitaría la frustración del autointerés. ${ }^{73}$

Adviértase que las consecuencias de aceptar este carácter del sistema democrático son importantes porque demuestran la existencia de un caso de ejercicio de acción colectiva en la que, para evitar problemas de coordinación como el dilema de los prisioneros o los

72 Una variante de esta justificación fue defendida por Carlos Nino; aunque también lo hizo en términos que, según diré, se asemejan a una justificación republicana. Cfr. Nino, Fundamentos de derecho constitucional, cit., pp. 199 y ss.

73 Es por esto que, por ejemplo, Dagger propone la existencia de un assurance game que tendrá como finalidad asegurar racionalidad y un altruismo condicional. Entonces, esto determinaría que se justifique el voto obligatorio. Además se otorga el mismo peso a cada uno a los intereses de los miembros del pueblo garantizando, por vía de la igualdad, la equidad del sistema. Cfr. Dagger, Civic virtues, cit. 
free riders e incluso que la legitimidad del sistema decaiga ante la posible falta de participación de los individuos, el Estado debe intervenir. En esta línea de análisis, como Nino sostuvo, es posible que los intereses de los sectores históricamente vulnerables no sean tomados en cuenta por parte de las políticas públicas. Y, si esto realmente fuera así, es irracional para ellos participar en elecciones si la incidencia de su voto individual es ínfima para la decisión colectiva que, de todos modos, no lo tendrá en cuenta dado que, y en especial, quienes están en las mismas condiciones no concurrirán a votar. ${ }^{74}$ Entonces, para un liberal medidas de paternalismo legítimo se encuentran justificadas y para un republicano se justifica la imposición de una virtud cívica que asegure esa participación. ${ }^{75}$ En suma, por una cuestión de justicia es necesario que todas las partes del pueblo tengan el mismo peso que el resto de la población.

Entiendo que, en función de lo que he dicho hasta aquí, existe una diferencia fundamental entre requerir algunas conductas y virtudes. Pienso que es posible justificar el requerimiento de virtudes cívicas; en cambio, las conductas que podrían ser impuestas a los ciudadanos sólo son necesarias para poner en prácticas o ejercer esas virtudes. Por ejemplo, es posible imponer la obligación al voto y, entonces, la conducta de votar dado que es la materialización de aquel debe ser ejercida. Sin embargo, ella no es impuesta de un modo intrínseco sino en tanto y en cuanto está vinculada, es relativa y dependiente de civic minded dispositions.

\section{Educación republicana: pública y constitucional}

Los ciudadanos deben ser educados en el gobierno de sus propios deseos. Repárese que para el republicanismo el altruismo limitado es un ingrediente relevante de su concepción de virtud cívica. A esto debe adicionarse, como hacen algunos autores, que las preferencias de los ciudadanos no son exógenas a la política; no son simplemente "dadas". ${ }^{76}$ Entonces, una función básica de la deliberación política y

74 Nino, Fundamentos de derecho constitucional, cit., pp. 608 y 609.

75 Sobre estos problemas, véase Dagger, Civic Virtues, cit., p. 113.

76 Véase, Sunstein, "Más allá del surgimiento republicano", cit., pp. 150 y ss. También, Dagger, Civic Virtues, cit., pp. 117 y ss. 
JUAN M. MOCOROA

de la educación debe consistir básicamente en la transformación de estas preferencias a partir de la discusión con otros y, en particular, en el respeto por los otros y por la conciencia y responsabilidad de la satisfacción del bien común. Sin que ello implique que la educación importe la homogeneización y el rechazo al pluralismo. Al contrario, la educación del buen ciudadano pasa por el respeto al "pluralismo cultural"; respeto por las tradiciones y la diversidad mientras promuevan la autonomía y la virtud cívica. Así, deberá respetar que los niños aprenden formas de vida y sistemas de creencias distintas a las suyas. Las virtudes cívicas son una disposición a actuar por el bien de la comunidad como un todo; de tal modo, sólo se puede desarrollar en una sociedad culturalmente diversa si los estudiantes obtienen un sentido realista de cómo los miembros de su comunidad difieren unos de otros. Y, pese a ello, siguen siendo partes de una misma aventura: vivir juntos. ${ }^{77}$

La educación para el republicanismo, entonces, consistiría en la capacidad o habilidad para dirigir una vida autogobernada y no dominada. Las escuelas públicas, por eso, deben formar buenos ciudadanos. Entre otras cosas, esto implica educar en los valores con los que una comunidad política está comprometida y, en especial, lograr que gobiernen sus deseos y pasiones. De modo que debería generar las posibilidades de promover autonomía y virtud cívica y, para esto, asentarse en los principios constitucionales que abraza la comunidad.

En este sentido, favorece la creación de escuelas pequeñas en las que se estimule la participación de los alumnos, un sentido de competencia, autoestima y efectividad que es esencial no sólo a la autonomía personal sino, también, a una ciudadanía responsable. Esto porque la participación en las actividades de la escuela incrementa las posibilidades de participación en los asuntos públicos. Y, con esto, mayor comunicación y participación. ${ }^{78}$

No obstante, formar buenos ciudadanos no implica educar soldados espartanos ni individuos privatizados preparados únicamente para seleccionar productos en el mercado. Lo primero porque la

77 Cfr. Dagger, Civic Virtues, cit., p. 127.

78 Idem. 
educación debe sustentarse en las cualidades de la deliberación democrática con otros, el ejemplo en la disputabilidad de las decisiones de la autoridad y la conciencia de vivir con otros y asegurar el cumplimiento de los objetivos de bien común. Lo segundo porque, justamente, lo que rechaza un modelo como el propuesto es individuos privatizados despreocupados por lo público.

\section{Democracia contestaria y deliberación política}

El republicanismo, según Pettit, se distancia de modo claro de ciertas visiones que lo identifican con una cosmovisión clásica que adopta una particular línea democrática -i. e., una que atiende únicamente a la participación política asentada sobre un conjunto de "libertades positivas" - . Para él, si el core de la tradición debe vincularse con la noción de no dominación, debe aceptarse que las situaciones a evitar incluyen casos en los que mayoría imponga su voluntad a otros de modo arbitrario. De ahí que no promueva una clase de democracia meramente electoral o mayoritaria. Aquí podría decirse que, para el republicanismo, la tiranía de los muchos, no pierde su carácter reprochable porque sean muchos quienes la apoyan. De lo contrario, las minorías podrían ver ignorados sus intereses, las normas carecerían de imparcialidad, no destinadas a satisfacer el bien común y, en fin, no generarían un gobierno deseable.

Por eso, la democracia debería ser representativa y limitada. Pettit la llama democracia contestataria o disputatoria; podría llamársela, también, deliberativa. Se trata del complemento necesario de la democracia electoral y en ella se da la contestación (o disputación) ex ante y ex post. Por esto, en fin, se trata de exigir a la mayoría electoral más disputabilidad. Promueve, así, el otorgamiento de derechos electorales y la efectiva oportunidad de disputar las decisiones de sus representantes. Esta visión requiere, como mínimo, tres cosas: $i$ ) procedimientos formales conocidos por todos para que las ramas del gobierno, y sus agencias, ejerzan su autoridad; ii) las decisiones adoptadas deben estar apoyadas en razones abiertas al debate público, y iii) foros institucionalizados donde los ciudadanos puedan disputar y hacer explícitas sus objeciones a las leyes y polí- 
JUAN M. MOCOROA

ticas estatales para demandar una respuesta; además, esta disputabilidad debería tener la posibilidad de obtener éxito. ${ }^{79}$

De este modo, el republicanismo de Pettit rechaza la arbitrariedad en la que podría incurrir, aun, la propia mayoría electoral; si no están limitados sus cursos de acción a las persecuciones de valores razonables e intereses del pueblo.

\section{Republicanismo, patriotismo constitucional y pluralismo cultural}

La filosofía republicana que reconstruí, en términos genéricos, sirve de marco para propuestas institucionales más concretas. Además, tiene la virtud de establecer un cuadro suficientemente político, amplio y deliberativo, del compromiso de las instituciones constitucionales. Y, con esto, de cómo deberían enfrentar los desafíos que formulan los reclamos de reconocimiento ciudadano fundados en diferencias culturales concretas. A partir de su concepción sobre las virtudes cívicas, el republicanismo se encuentra dotado de mejores herramientas frente al desafío de las demandas de reconocimiento diferenciado realizado por minorías culturales. Como sostuviera Robert Post:

Los derechos especiales que protegen aspectos de la identidad del grupo inconsistentes con los aspectos del individualismo considerados necesarios para la solidaridad nacional son pro tanto ilegítimos. Por ejemplo, si se entiende que la necesidad individual de una identidad de grupo requiere formas de afiliación voluntarias, los derechos especiales que impiden en forma significativa la posibilidad de salir de grupos debe decretarse ilegítima. ${ }^{80}$

79 Cfr. Pettit, Philip, "Civic Republican Theory”, en Martí, José Luis y Pettit, Philip, A Political Philosophy in Public Life: Civic Republicanism in Zapatero's Spain, Princeton-Oxford, Princeton University Press, 2010, cap. 2. Ampliar en Pettit, Republicanismo, cit; Lovett, Frank y Pettit, Philip, "Neorepublicanism: A Normative and Institutional Research Program", Annual Review of Political Science, núm. 12, 2009, pp. 11-29.

${ }^{80}$ Cfr. Post, Robert, "Constitucionalismo democrático y heterogeneidad cultural”, trad. de Laura Saldivia y Camila Blanco, con la colaboración de Samanta Biscardi, Revista Jurídica de la Universidad de Palermo, año 9, núm. 1, 2008, p. 18. 
Adviértase cómo esta posición delimita las demandas identitarias a la "solidaridad nacional". Se trata de un concepto esencialmente político que vincula otros conceptos bien densos: lealtad, respeto, patriotismo. Ahora bien, las comunidades políticas contemporáneas, generalmente, prefieren que su destino sea gobernado por una Constitución. Esta determina, en definitiva, cómo es que se diseñarán los proyectos colectivos de Nación. De esta manera, las Constituciones suelen ser producto de una narrativa colectiva incardinada a generar dos elementos relevantes: autogobierno y libertad. La solidaridad constitucional, como prefiero, debe apoyarse sobre esas dos nociones. De todos modos, aquel texto es sólo el punto de apoyo de una práctica que determinará los intrincados semánticos de nuestro quehacer común. Ahora, en los intersticios de sus indefiniciones textuales compiten diversas concepciones sobre cuál es ese mejor destino común, y, con ello, la mejor forma de concebirnos como comunidad política. Allí se resolverán los inevitables desacuerdos sobre cómo moldear un futuro común.

Es aquí donde aparecen los desafíos de las minorías culturales, en algún sentido, en procura de un éxodo de ese común porvenir. Es que las normas constitucionales poseen la potencia de generar las lealtades que reclaman para sí dado que son una consecuencia del autogobierno colectivo. Vale decir, en tanto y en cuanto sean normas autónomas; dictadas en ejercicio de la autonomía pública de la que habla Habermas. Ahora bien, si esto no ocurre -i. e., si son impuestas desde fuera-, generar las lealtades fuertes que reclama el republicanismo sólo sería una ilusión. No obstante, debo destacar ciertos compromisos que yacen en el seno de esta visión comunitaria constitucional. Estos ponen el acento en ciertas condiciones democrático procedimentales de legitimidad de la propia Constitución. ${ }^{81}$ Según estas condiciones, la posibilidad del disenso está siempre presente; no como desviación - no querida- de la necesidad de vivir en común. Por el contrario, la propia noción de lo colectivo asume como necesario e inerradicable la existencia misma de esos desacuerdos. Por cuanto el disenso, en definitiva, aparecerá cada vez que se in-

81 Sobre estos fundamentos, véase Riberi, Pablo C., Teoría de la representación política. Crisis y desafíos del Estado contemporáneo, Santa Fe, Rubinzal Culzoni, 2014, cap. III (Fundamentos para una república exigente). 
JUAN M. MOCOROA

tente plasmar una idea acerca de lo que el destino común requiere; cuál es la mejor forma de reconstruir nuestra práctica constitucional y, así, delinear cuáles serán los objetivos que, en el futuro, intentará cumplir.

Hecho esto, debo enfatizar ciertas derivaciones de los presupuestos a los que hice referencia. Esto implica rechazar la existencia de intérpretes privilegiados del destino de la comunidad; al menos, en cuanto ellos sean diferenciados de sus mismos integrantes.

Pero también excluye que algunos sujetos intenten sustraerse de la autoridad del derecho creado en aquellas condiciones. Este es el compromiso que reclama el "patriotismo constitucional". ${ }^{2}$ Como refiere Pablo Riberi, para la intelección de este concepto es menester excluir cualquier hiato entre él y los fundamentos políticos de la Constitución. A partir de lo cual, es posible interpretar que son estos últimos los que generan al primero, y no a la inversa. Para él, por eso, el "patriotismo constitucional" es:

...de matriz republicana y democrática; un patriotismo cuyas raíces de naturaleza "políticas" y ciudadanas son vivenciadas por quienes comparten sentimientos de identidad, libertad e igualdad... [S]e propone pensar y amar la patria a partir del principio del autogobierno y de la soberanía popular. Solo admitiendo imperfectos e inacabados procesos deliberativos con nuestros conciudadanos; solo insertándonos dentro de la res publica es posible experimentar y comprender este temperamento patriótico. ${ }^{83}$

82 Carlos Nino puso en duda la utilidad teórica, la conveniencia filosófica y la deseabilidad política del término. Para él, no era claro si se trata de un esquema de valores, derechos y obligaciones que se vincula con una actitud de lealtad y están justificados por la vigencia convencional de una Constitución, cualquiera sea su contenido; o bien por los principios ideales que se consideran válidos, sean o no el contenido de la Constitución positiva. Lo primero, para él, sería contraintuitivo. Lo segundo, nos colocaría frente a la superfluidad de la Constitución para el razonamiento práctico. Cfr. Nino, Carlos S., "La Constitución como Convención", en id., Una teoría de la justicia para la democracia. Hacer justicia, pensar la igualdad y defender las libertades, Gustavo Maurino (ed.), Buenos Aires, Siglo XXI Editores, 2013, p. 26. Por lo que digo en el cuerpo del texto, no coincido con este autor.

83 Cfr. Riberi, Pablo C., "Patriotismo constitucional: letanía para una emoción urgente”, Debates De Actualidad, año XXV, núm. 203, p. 139. 
Se trata, entonces, de un compromiso respecto de los principios constitucionales del sistema de los derechos que fundamentan la participación en el ámbito político por parte de los ciudadanos y que, también, justifican la selección de identidades diferenciadas, siempre y cuando sean respetuosas de las condiciones públicas de vivir colectivamente en una comunidad política. Es que, tal como expresan Tribe y Dorf en otro contexto, una Constitución pretende realizar una

Acción bastante confiada y valerosa, crear una nación mediante palabras: palabras que no se dirigen a un rey foráneo o a un poder distante sino a la propia entidad que se crea a través de estas palabras; palabras que van dirigidas a un gobierno que pretende constituir; palabras que van dirigidas a las futuras generaciones de ciudadanos que darán vida a ese gobierno en años venideros. ${ }^{84}$

De esta forma, en términos teóricos, con el dictado de una Constitución sus autores no sólo expresan por medio del lenguaje un conjunto de términos. Además, hacen algo con ello. Esto es, a la fuerza ilocucionaria del lenguaje ha de sumársele su efecto perlocucionario. De este modo, cuando profieren esas palabras, a no dudarlo, fundan una comunidad política. Su resultado pragmático será una serie encadenada de lealtades subsiguientes, prácticas de comprensión mutua, respeto por sus compromisos y las bases de su configuración futura. Todo lo cual, tendrá la virtud política de generar obediencia y acatamiento reflexivo por venideras generaciones. En fin, tendrá la potencia de regir y encauzar el futuro de esa comunidad.

En este sentido, el constitucionalismo democrático que defiendo, asentado en una filosofía política republicana, reclama la presuposición de una voz compartida en la construcción de las cláusulas constitucionales. De tal modo, esto se vincula con dos cuestiones que tuvimos oportunidad de analizar: $i$ ) la obligatoriedad del voto $y$ ii) una educación democrática basada en los valores constitucionales de autonomía y pluralismo. En todo caso, la finalidad siempre es garantizar un robusto autogobierno colectivo.

84 Cfr. Tribe, Lawrence y Dorf, Michael, Interpretando la Constitución, trad. de Jimena Aliaga Gamarra, Lima, Palestra Editores, 2010, p. 43. 
JUAN M. MOCOROA

Y, sépase, en esta tarea no puede servir de excusa un planteamiento multiculturalista. Dado que, a partir de la estructura dialógica que se propicia, la construcción de esa constitución no puede asimilarse con la imposición de un grillete desde afuera. Sino que, antes bien, se trata de la determinación de una identidad nacional y constitucional construida a partir de las luchas deliberativas ocurridas diacrónicamente en torno a los significados de aquel texto.

Además, es la propia legitimidad de la Constitución la que se debate en esas constantes diatribas. Es que esa legitimidad depende de "la existencia de una relación de reconocimiento de parte del pueblo a su respecto". ${ }^{85}$ Finalmente, permitirá "analizar las practicas y las concepciones mediante las cuales los derechos constitucionales fueron establecidos históricamente en el contexto de controversias culturales". ${ }^{86}$ Y, con esto, lograr cohesión social dentro de una estructura política heterogénea, como dicen Post y Siegel.

Sin embargo, son necesarios unos comentarios adicionales sobre qué tipo de Constitución sería y, además, cuál sería su contenido. Como sostuviera Steven Lukes, la lista de derechos consagrada debería ser razonablemente corta y abstracta. La télesis de esta posición es la posibilidad de asegurar consenso en la vida política contemporánea. Aun cuando el desacuerdo surja al momento de concretar esos derechos abstractos. ${ }^{87} \mathrm{Si}$ bien es cierto que, con esta propuesta, esos disensos no se excluyen es posible pensar que determinan un marco adecuado para su solución. También adviértase que ellos se basarían en el "hecho del pluralismo" y no, por el contrario, en que los ciudadanos no creen en la propia idea de derechos.

Ahora bien, abstractos y pocos derechos no excluyen desacuerdos sucesivos. En sociedades heterogéneas de este tipo, debería depositarse en las asambleas legislativas la responsabilidad última de su resolución; siempre y cuando ellas funcionen razonablemente

85 Tomo esta idea de Post, Richard y Siegel, Reva, Constitucionalismo democrático. Por una reconciliación entre Constitución y pueblo, trad. de Leonardo García Jaramillo, Buenos Aires, Siglo XXI Editores, 2013, p. 33.

86 Cfr. Post y Siegel, Constitucionalismo democrático, cit., p. 44.

87 Lukes, "Cinco fábulas sobre los derechos humanos", cit. 
bien al representar los intereses de los ciudadanos. Es que, en política, siempre se trata de establecer cómo solucionaremos esos desacuerdo, tal y como dice Waldron. Deberíamos pensar, entonces, qué institución está mejor preparada, en términos relativos y comparativos respecto de otros arreglos institucionales, dada su legitimidad democrática para actuar como solucionador de conflictos. ${ }^{88}$

Todo esto debería imponer rigurosas condiciones de tolerancia a minorías culturales. Sin embargo, no propone una actitud de indiferencia. Por el contrario, al aceptar aquella noción se reconoce que existe una situación asimétrica entre las mayorías de la ciudadanía y los miembros de esos grupos desaventajados. Se trata de una práctica política que, si bien asume una desaprobación moral a algunas de las actividades de los grupos culturales, no interfiere con ellos sino sólo cuando sus prácticas identitarias socaven las condiciones de deliberación política y democrática. ${ }^{89}$ En este sentido, a las minorías disidentes se les hace una invitación: deben transformar los elementos caracterizantes de su identidad. En términos de Habermas, se nos propone a todos los miembros de estas sociedades pluralistas la adopción de una identidad amarrada a los principios constitucionales anclados en la cultura política, y no en las orientaciones éticas fundamentales de una forma de vida cultural predominante en una comunidad política. ${ }^{90}$

Por supuesto, una pregunta relevante aquí sería cuál es la diferencia con una propuesta liberal. En especial, con un liberalismo político a la Rawls. El problema con una posición como esta es que efec-

88 Sobre esta forma de argumentar, véase Waldron, Jeremy, "The Core of the Case Against Judicial Review", The Yale Law Journal, vol. 115, núm. 6, y Rodríguez Moreno Alcalá, Diego, Control judicial de la ley y derechos fundamentales, Madrid, CEC, 2011.

89 Sobre el alcance conceptual de la "tolerancia” y sus límites, Williams, Bernard, "La tolerancia, ¿una cuestión política o moral?", en id., En el principio era la acción. Realismo y moralismo en el argumento político, trad. de Adolfo García de la Sienra, México, Fondo de Cultura Económica, 2012, pp. 169-181, y Garzón Valdez, Ernesto, "«No pongas tus sucias manos sobre Mozart». Algunas consideraciones sobre el concepto de tolerancia", en id., Derecho, ética y política, Madrid, CEC, 1993, pp. 401-415.

90 Sobre esto, véase Habermas, "La lucha por el reconocimiento en el Estado democrático de derecho", cit. 
JUAN M. MOCOROA

túa una distinción tajante entre lo público y lo privado. Y, en virtud de esta tajante separación, condena cualquier reclamo diferenciador al ámbito privado. ${ }^{91}$ Entonces, carecería de criterios adecuados para la resolución de los conflictos que podrían presentarse entre, como dice Benhabib, "los imperativos constitucionales y las prácticas de ciertos grupos culturales". ${ }^{92}$

De ahí que sea conveniente proponer un conjunto de principios normativos en los que se pueda enmarcar la convivencia con estas minorías culturales que reclaman por derechos diferenciados. Estos principios, deberían ser de la suficiente amplitud y politicidad para realizar dos cuestiones importantes: proteger las diferencias y respetar marcos de convivencia democrática deliberativa en los que se asienta el patriotismo constitucional. Benhabib, correctamente, propone tres principios que deberían dar fundamento a la esfera jurídica; estos son: i) reciprocidad igualitaria -i. e. los miembros de minorías culturales no deben tener derecho a un grado menor de derechos que los miembros de la mayoría-, ii) autoadscripción voluntaria - i. e. una persona no puede ser asignada automáticamente a un grupo cultural, religioso o lingüístico en virtud de su nacimiento; esto es consecuencia de una decisión consciente y reflexiva-, y iii) libertad de salida y asociación -i. e. libertad irrestricta para salir del grupo de adscripción, aunque pueda ir acompañada de la pérdida de privilegios formales o informales-.

Estos principios son relevantes para la definición de las competitivas identidades de los miembros de las sociedades plurales contemporáneas. De todos modos, no nos dicen nada respecto de cómo debe conformarse un elemento esencial para una propuesta suficientemente política como la que me interesa, el demos democrático. Sobre esto, en conjunción con lo dicho sobre el patriotismo constitucional, debería pensarse que este colectivo es construido y reconstruido a lo largo del tiempo, de un modo diacrónico. Además, en esa construcción debe aceptarse que la centralidad de una Constitución que respete aquellos principios normativos y la necesidad

91 Cfr. Benhabib, Las reivindicaciones de la cultura, cit., p. 187.

92 Ibidem, p. 189. 
de no dominación de los individuos deviene necesaria. Como sostiene Habermas:

La delimitación social del pueblo propio de un Estado (Staatsvolk) se deriva de circunstancias históricas que son externas al sistema de los derechos y a los principios del estado de derecho. Dicha delimitación decide sobre el conjunto de las personas que conviven en un territorio y están obligados por la constitución, es decir, por la decisión de los padres fundadores de regular legítimamente con los medios del derecho positivo su vida en común; en su calidad de descendientes han dado implícitamente su conformidad (y, en cuanto ciudadanos inmigrantes, de modo explicito) para proseguir un proyecto constitucional con el que se han encontrado. ${ }^{93}$

\section{CONCLUSIONES}

Este trabajo tuvo un camino intrincado, para enfrentar un problema complejo. Recorrí diversas posiciones filosóficas en búsqueda de una propuesta institucional suficientemente política para hacer frente al "hecho del pluralismo" y las demandas de reconocimiento reivindicadas por determinadas minorías culturales. Finalmente, mi preferencia fue explícita acerca de una particular forma de ver la tradición republicana. Esta posición me sirvió para reivindicar la defensa de ciertas virtudes cívicas. En especial, la justificación del voto y la educación obligatoria asentada en principios constitucionales de autonomía y pluralismo. A partir de lo cual, defendí una variante específica del "patriotismo constitucional".

Además, puse en entredicho una respuesta afirmativa a la pregunta que titula este escrito. En síntesis, no creo que seamos prisioneros de nuestra identidad como algunas posiciones radicales asumirían. Al contrario, creo que éstas deberían ser asumidas como construidas en diálogo con otros. Intenté mostrar, también, cómo la estructura institucional que propicia el constitucionalismo político y democrático podría resultar adecuado para lograr su protección

93 Cfr. Habermas, "La lucha por el reconocimiento en el Estado democrático de derecho", cit., p. 181. 
JUAN M. MOCOROA

y tutela. En particular, porque brinda las herramientas necesarias para asegurar la no dominación de cualquier individuo, aseguraría condiciones adecuadas de deliberación y, por último, sienta las bases adecuadas para justificar un amplio patriotismo secular y constitucional.

Aquí debería responder dos posibles objeciones. Por un lado, mi acercamiento mantendría la invisibilidad de las diferencias y, por otro, reclamo que las minorías que conforman grupos culturales diversos sean presas de una nueva identidad que tiende a la homogeneización. Pueden ser ciertos ambos reproches. De todos modos, respecto del primero, mi propuesta no impide reivindicar esas diferencias ni que se establezcan políticas protectorias de ellas. Sólo, insisto, reclama conciencia sobre la necesidad de que aquellas minorías se sientan parte de la construcción del derecho; de "su" derecho. Y, para ello, no existe otra forma plausible en un entramado institucional que exigir virtudes cívicas y compromiso con lo público. De lo contrario, sólo la secesión interna y exclusión tendría sentido, y esto es inaceptable. La segunda objeción, es más radical. Empero, pienso, la única forma de hacerle frente es insistir en la necesidad del autogobierno colectivo. No se trata de crear nuevas prisiones, con nuevos barrotes. Esta vez, convertidos en artículos constitucionales. En efecto, se trata de asumir el aspecto emancipador de la deliberación política. A tal fin, debatir sobre la configuración adecuada del destino común es insoslayable. Ahora bien, el único modo legítimo de hacerlo es a través de la participación política y la asunción de cierto sesgo por el patriotismo constitucional que defendí en este trabajo.

\section{REFERENCIAS BIBLIOGRÁFICAS}

Bellamy, Richard, Constitucionalismo político. Una defensa republicana de la democracia, trad. de Jorge Urdánoz Ganuza y Santiago Gallego Aldaz, Madrid, Marcial Pons, 2010.

BENHABIB, Seyla, Las reivindicaciones de la cultura. Igualdad y diversidad en la era global, trad. de Alejandra Vassallo, Buenos Aires, Katz, 2006. 
Berlin, Isaiah, "Dos conceptos de libertad", en id., Sobre la libertad, Henry Hardy (ed.), trad. de Julio Bayón et al., Madrid, Alianza, 2009.

BerTomeu, María J. y Domènech, Antoni, "Introducción: algunas observaciones sobre método y substancia normativa en el debate republicano", en BeRTOMEU, María Julia et al., Republicanismo y democracia, Buenos Aires, Miño y Dávila, 2005.

Colón-Ríos, Joel y HeviA, Martín, “De la redistribución al reconocimiento", en AlEgre, Marcelo y Gargarella, Roberto (eds.), El derecho a la igualdad. Aportes para un constitucionalismo igualitario, 2a. ed. ampliada, Buenos Aires, Abeledo-Perrot, 2012.

Comanducci, Paolo, "Derechos humanos y minorías: un acercamiento analítico neo-ilustrado", trad. de Francesca Galgano, Isonomía. Revista de Teoría y Filosofía del Derecho, núm. 3, 1995.

DAGger, Richard, Civic Virtues, Nueva York-Oxford, Oxford University Press, 1997.

Dworkin, Ronald, La democracia posible. Principios para un nuevo debate político, trad. de Ernest Weikert García, Barcelona, Paidós, 2007.

-_- Virtud soberana. La teoría y la práctica de la igualdad, trad. de María Julia Bertomeu, Barcelona, Paidós, 2003.

FARRELl, Martín, “¿Hay derechos comunitarios?”, Doxa. Cuadernos de Filosofía del Derecho, núm. 17-18, 1995.

FRASER, Nancy, “¿De la redistribución al reconocimiento? Dilemas en tomo a la justicia en una época "post-socialista»", en Iustitia Interrupta: Reflexiones críticas desde la posición "postsocialista”, Santa Fe de Bogotá, Siglo de Hombres Editores, 1997.

GARgARElla, Roberto, Las teorías de la justicia después de Rawls. Un breve manual de filosofía política, Madrid, Paidós, 1999.

GARZón VALDEZ, Ernesto, “«No pongas tus sucias manos sobre Mozart». Algunas consideraciones sobre el concepto de tolerancia”, Derecho, ética y política, Madrid, CEC, 1993. 
JUAN M. MOCOROA

- - - "Cinco confusiones acerca de la relevancia moral de la diversidad cultural", en Instituciones suicidas. Estudios de ética y política, México, Paidós, 2000.

GuiÑAZÚ, Claudio, "El sistema penal frente a la diversidad cultural: el caso «Ruiz, J. F.»", en RossetTi, Andrés y Álvarez, Magdalena I. (coords.), Derecho a la igualdad. Un análisis desde el método de casos, Córdoba, Advocatus, 2010.

Gutmann, Amy, "Introducción”, en TAYlor, Charles, El multiculturalismo y "la política del reconocimiento", 2a. ed., trad. de Mónica Utrilla de Neira et al., México, Fondo de Cultura Económica, 2009.

HABERMAS, Jürgen, "La lucha por el reconocimiento en el Estado democrático de derecho", en TAYLOR, Charles, El multiculturalismo y "la política del reconocimiento", 2a. ed., trad. de Mónica Utrilla de Neira et al., México, Fondo de Cultura Económica, 2009.

KYMLickA, Will, "Igualitarismo liberal y republicanismo cívico: ¿amigos o enemigos?", trad. de Tomás Fernández Aúz, en Ovejero, Félix, et al. (eds.), Nuevas ideas republicanas. Autogobierno y libertad, Barcelona, Paidós, 2004.

_-_, Ciudadanía multicultural, Barcelona, Paidós, 1996.

LovetT, Frank y PetTit, Philip, "Neorepublicanism: a Normative and Institutional Research Program", Annual Review of Political Science, núm. 12, 2009.

LuKEs, Steven, "Cinco fábulas sobre los derechos humanos", en Shute, Stephen y Hurley, Susan (eds.), De los derechos humanos. Las conferencias Oxford Amnesty de 1993, Madrid, Trotta, 1998.

Macintyre, Alasdair, Tras la virtud, trad. de Amelia Valcárcel, Barcelona, Crítica, 1987.

MARTí, José L., La republica deliberativa. Una teoría de la democracia, Madrid, Marcial Pons, 2004.

Nino, Carlos S. "La Constitución como convención", en Maurino, Gustavo (ed.), Una teoría de la justicia para la democracia, Buenos Aires, Siglo XXI Editores, 2013. 
-—-, Fundamentos de derecho constitucional. Análisis filosófico, jurídico y politológico de la práctica constitucional, Buenos Aires, Astrea, 2002.

-——, "Kant versus Hegel, otra vez", La Política. Revista de Estudios sobre el Estado y la sociedad, Barcelona, núm. 1, 1996.

OKIN, Susan M., Is Multiculturalism Bad for Women?, Princeton University Press, 1999.

Ovejero, Félix et al., "Introducción”, en Ovejero, Félix et al. (eds.), Nuevas ideas republicanas. Autogobierno y libertad, Barcelona, Paidós, 2004.

Patten, Allan, "La crítica republicana al liberalismo", trad. de Sandra Girón, en Ovejero, Félix et al., Nuevas ideas republicanas. Autogobierno y libertad, Barcelona, Paidós, 2004.

PEÑA, Javier, “Ciudadanía republicana y virtud cívica”, en BERTOMEU, María Julia et al., Republicanismo y democracia, Buenos Aires, Miño y Dávila, 2005.

PetTit, Philip, Republicanismo. Una teoría sobre la libertad y el gobierno, trad. de Antoni Doménech, Barcelona, Paidós, 1999.

-_- "La libertad republicana y su trascendencia constitucional", en Bertomeu, María Julia et al., Republicanismo y democracia, Buenos Aires, Miño y Dávila, 2005.

-_- "Civic Republican Theory”, en Martí, José Luis y Pettit, Philip, A Political Philosophy in Public Life: Civic Republicanism in Zapatero's Spain, Princeton-Oxford, Princeton University Press, 2010.

Post, Robert, "Constitucionalismo democrático y heterogeneidad cultural", trad. de Laura Saldivia y Camila Blanco, Revista Jurídica de la Universidad de Palermo, año 9, núm. 1, 2008.

Post, Richard y Siegel, Reva, Constitucionalismo democrático. Por una reconciliación entre Constitución y pueblo, trad. de Leonardo García Jaramillo, Buenos Aires, Siglo XXI Editores, 2013.

RAWLS, John, "Justice as Fairness: Political not Metaphysical", Philosophy and Public Affairs, vol. 14, núm. 3, 1985. 
JUAN M. MOCOROA

———, El liberalismo político, trad. de Antoni Domènech, Madrid, Crítica, 2004.

Riberi, Pablo C., Teoría de la representación política. Crisis y desafío del Estado Contemporáneo, Santa Fe, Rubinzal Culzoni, 2014.

- - - "Patriotismo constitucional: letanía para una emoción urgente”, Debates de Actualidad, Santa Fe, año XXV, núm. 203, 2010.

Rivera López, Eduardo, "Las paradojas del comunitarismo", Doxa. Cuadernos de Filosofía del Derecho, núm. 17-18, 1995.

RoDRÍGUEz ABASCAL, Luis, "El debate sobre los derechos de grupo", en DíAz, Elías y Colomer, José Luis (eds.), Estado, justicia, derechos, Madrid, Alianza, 2002.

Rodríguez Moreno AlCALÁ, Diego, Control judicial de la ley y derechos fundamentales, Madrid, CEC, 2011.

SAndel, Michael, Democracy's Discontent. America in Search of a Public Philosophy, Cambridge, Havard University Press, 1998.

-_- Justicia ¿Hacemos lo que debemos?, trad. de Juan Pedro Campos Gómez, Barcelona, Debate, 2011.

-_- El liberalismo y los límites de la justicia, trad. de María Luz Melón, Barcelona, Gedisa, 2000.

SEN, Amartya, Identidad y violencia. La ilusión del destino, trad. de Verónica Weinstabl y Servanda M. de Hagen, Buenos Aires, Katz, 2008.

SKINNER, Quentin, "Las paradojas de la libertad política", trad. de Verónica Lafrieri, en OvEJERo, Félix et al. (eds.), Nuevas ideas republicanas. Autogobierno y libertad, Barcelona, Paidós, 2004.

Sunstein, Cass, "Más allá del surgimiento republicano", trad. de Verónica Lafrieri, en Ovejero, Félix et al. (eds.), Nuevas ideas republicanas. Autogobierno y libertad, Barcelona, Paidós, 2004.

TAYLOR, Charles, "La policía del reconocimiento", en El multiculturalismo y "la política del reconocimiento", 2a. ed., trad. de Mónica Utrilla de Neira et al., México, Fondo de Cultura Económica, 2009. 
Tomkins, Adam, Our Republican Constitution, Oxford, Hart, 2005.

TRIBE, Lawrence y DoRF, Michael, Interpretando la constitución, trad. de Jimena Aliaga Gamarra, Lima, Palestra Editores, 2010.

VÁzQuEz, Rodolfo, Liberalismo, Estado de derecho y minorías, México, Paidós, 2001.

WALDRon, Jeremy, "Minority Cultures and the Cosmopolitan Alternative", en KyMLICKA, Will (ed.), The Rights of Minority Cultures, Oxford, Oxford University Press, 1995.

-_- " "The Core of the Case Against Judicial Review", The Yale Law Journal, vol. 115, núm. 6.

-_- Derecho y desacuerdos, trad. de José L. Martí y Águeda Quiroga, Madrid, Marcial Pons, 2005.

WAlzer, Michael, "Comentario", en TAYlor, Charles, El multiculturalismo y "la política del reconocimiento", 2a. ed., trad. de Mónica Utrilla de Neira et al., México, Fondo de Cultura Económica, 2009.

Williams, Bernard, "La tolerancia, ¿una cuestión política o moral?”, en id., En el principio era la acción. Realismo y moralismo en el argumento político, trad. de Adolfo García de la Sienra, México, Fondo de Culura Económica, 2012. 